\title{
The Alzheimer's Disease-Associated Presenilins Are Differentially Phosphorylated Proteins Located Predominantly within the Endoplasmic Reticulum
}

\author{
Jochen Walter,* Anja Capell,* Jürgen Grünberg,* Brigitte Pesold,* \\ Alice Schindzielorz,* Reinhard Prior, ${ }^{\dagger}$ Marcia B. Podlisny, ${ }^{\neq}$Paul Fraser, ${ }^{\text {\&\| }}$ \\ Peter St. George Hyslop, ${ }^{\text {\&ll }}$ Dennis J. Selkoe, ${ }^{\ddagger}$ and Christian Haass* \\ *Central Institute of Mental Health, Department of Molecular \\ Biology, Mannheim, Germany \\ ${ }^{\dagger}$ Departments of Neurology and Neuropathology, University of \\ Düsseldorf, Düsseldorf, Germany \\ ${ }^{\ddagger}$ Center for Neurologic Diseases, Brigham and Women's Hospital and \\ Harvard Medical School, Boston, Massachusetts, U.S.A. \\ §Department of Medicine (Neurology), Center for Research into \\ Neurodegenerative Diseases, University of Toronto, Toronto, \\ Ontario, Canada \\ "Division of Neurology, Department of Medicine, The Toronto \\ Hospital, Toronto, Ontario, Canada
}

\begin{abstract}
Background: Alzheimer's disease $(\mathrm{AD})$ is a progressive neurodegenerative disorder characterized by the deposition of extracellular senile plaques composed of amyloid $\beta$-peptide $(\mathrm{A} \beta)$. Whereas most cases of $\mathrm{AD}$ occur sporadically, about $10 \%$ of $\mathrm{AD}$ cases are inherited as a fully penetrant autosomal dominant trait. Mutations in the recently cloned Presenilin genes (PS-1 and PS-2) are by far the most common cause of early onset familial $\mathrm{AD}$. Materials and Methods: Cellular expression of endogenous and overexpressed PS proteins was analyzed by immunocytochemistry and metabolic labeling followed by immunoprecipitation. In vivo phosphorylation sites of PS proteins were analyzed by extensive mutagenesis.

Results: PS-1 as well as PS-2 proteins were localized predominantly within the endoplasmic reticulum (ER). However, small amounts of the PS proteins were detected within the Golgi compartment, where they colocalize with the $\beta$-amyloid precursor protein ( $\beta$ APP). The PS-2 protein was found to be highly phosphorylated,
\end{abstract}

whereas very little phosphorylation was observed for PS-1. The selective phosphorylation of PS-2 occurs exclusively on serine residues. In vivo phosphorylation of PS-2 was mapped to serine residues 7, 9, and 19 within an acidic stretch at the $\mathrm{N}$ terminus, which is absent in PS-1. Casein kinase (CK)-1 and CK-2 were shown to phosphorylate the $\mathrm{N}$ terminus of PS-2 in vitro.

Conclusions: The majority of PS proteins were detected in the ER where little if any proteolytic processing of $\beta A P P$ was reported. ER retention of PS proteins might occur by intramolecular aggregation. Small amounts of PS proteins were also detected in the Golgi where they colocalized with $\beta A P P$. This might suggest that potential interactions between PS proteins and $\beta$ APP could occur within the Golgi. Selective phosphorylation of PS-2 proteins within the acidic domain missing in PS-1 indicates differences in the biological functions and regulation of the two highly homologous proteins. 


\section{INTRODUCTION}

Alzheimer's disease (AD) is the most common form of dementia. AD is characterized by the massive and invariable accumulation of senile plaques in certain regions of the brain (1). The degree of the dementia appears to correlate to some extent with the size of cortical area affected by $A \beta$ depositions, suggesting a causal role of $A \beta$ in $A D(2)$. Senile plaques are predominantly composed of amyloid $\beta$-peptide $(A \beta)$, a proteolytic product of the $\beta$-amyloid precursor protein ( $\beta$ APP) $(1,3,4)$.

Most of the AD cases appear to occur sporadically, however in approximately $10 \%$ of the cases the disease can be inherited as an autosomal dominant trait resulting in early onset familial Alzheimer's disease (FAD). FAD was mapped so far to at least three different loci, localized on human chromosomes 1, 14, and 21 (5-9). In addition, a polymorphism in a gene encoding apolipoprotein $\mathrm{E}$ has been shown to decrease the age of onset of $\mathrm{AD}$ and to increase the risk for the disease (10). The gene on chromosome 21 turned out to be the $\beta$ APP gene. To date, five different $A D$-linked mutations were found within the $\beta$ APP gene (11). These mutations are localized close to the cleavage sites of $\beta$ APP processing enzymes (12). All of these mutations were shown to influence the processing of $\beta$ APP in a pathological manner, by either increasing the total amount of secreted $A \beta$ or by producing $A \beta$ peptides with elongated $C$ termini (13-16). However, mutations in the $\beta$ APP gene account for only a very small minority of FAD cases.

In contrast, genes belonging to the Presenilin (PS) gene family were found to be involved in about $40-50 \%$ of the early onset FAD cases. Two homologous genes, PS-1 and PS-2, located on human chromosome 14 (PS-1) and human chromosome 1 (PS-2), respectively, were cloned recently $(9,17-19)$. The PS genes encode proteins which are $64 \%$ homologous and might adopt a potential seven transmembrane domain structure (Fig. 1a) (18-20). Within the PS-1 gene at least 30 different mutations have been identified so far, while only two mutations were localized to the PS-2 gene (17-28). All mutations occur at positions which are conserved in both PS genes and seem to cluster within the putative transmembrane domain 2 (TM2) and the large hydrophilic loop between TM6 and TM7 indicating important functional properties of these domains (20). Depending on the mutation, they can cause onset of $\mathrm{AD}$ between the age of 25 and 85 years
(17-19,21-28). This finding clearly indicates that the mutations can have mild or severe effects on the biological function or pathological misfunction of PS proteins. The PS genes are transcribed in a variety of different tissues and are not brain specific $(17-19,29)$. However, within the human brain PS-1 as well as PS-2 transcripts are expressed in regions that are affected most severely during the disease $(29,30)$. Although the physiological function of the PS proteins is unknown, sequence homologies to the Caenorhabditis elegans genes spe-4 and sel-12 suggest a potential role of the PS proteins in either vesicular sorting and trafficking or in notch signaling $(31,32)$. Recent experiments analyzing the expression of recombinant PS- 2 cDNAs in transfected cells revealed that flagged PS-2 proteins are expressed as membrane bound $\sim 45-\mathrm{kD}$ proteins and might be located within an intra-membranous network, perhaps the endoplasmic reticulum (ER) (29). Here, we report on the cellular localization and posttranslational modifications of PS- 1 as well as PS-2 proteins.

\section{MATERIALS AND METHODS}

\section{In Vitro Mutagenesis and Transfection}

C-terminal deletions of the PS-2 protein were constructed by introducing stop codons after the putative transmembrane domains (TM) 7, 6, 5, and 4 using PCR. The following oligonucleotide was used as a forward primer: 5'-CCGAATTCCAAGTGTCC GGGATT-3' (PS2forward). The following oligonucleotides were used as a reverse primer: 5' - CCGGATCCCTACTTCTTGAACACAGC-3' (PS2TM7stop), 5'-CCGGATCCCTACCCTTTGGG A CACAG-3' (PS2TM6stop), 5'-CCGGATCCCTAGT ACTTGATGAACAC-3' (PS2TM5stop), 5'-CCGG GATCCCTACCAGTGGATGCACAC-3' (PS2TM4stop). The forward primer contained an EcoRI restriction site, and the reverse primer a BamHI restriction site and a STOP codon. After PCR using the wt PS-2 cDNA as a template, the isolated products were restricted with BamHI and EcoRI and cloned into the expression vector pSG5 (Stratagene, La Jolla, CA, U.S.A.). The deletions were confirmed by DNA sequencing. The corresponding PS-1 constructs were generated using the same strategy.

Construction of the hybrid molecules (PS1/NT PS-2, PS-2/NT PS-1): the $\mathrm{N}$ terminus of PS-2 (between the start codon and TM1) was added to PS- 1 as follows. For the amplification of 
the coding sequence of PS- 1 between TMl and the native stop codon we used the following primers: 5'-CCGAATTCAAGCATGTGATCATGC TCTTTGTC-3' (PS-1 TMlforward) and 5'-CCG GATCCGCAAATATGCTAGAT-3' (PS-1 1660 reverse). The PCR product was restricted with BamHI and EcoRI and subcloned into pSG5. The PS-2 $\mathrm{N}$ terminus was amplified using the following primers: 5'-CCGAATTCCCAAGTGTC CGGGATT- $3^{\prime}$ (PS-2 $\mathrm{N}^{\prime}$ forward) and 5'-CCGAA TTCCGCTCCGTATTTGAGGGTCAG-3' (PS-2 N' reverse). The PCR fragment was restricted by $E c o$ RI and subcloned into the above described pSG5 containing the PS-1 sequence. The EcoRI site creates two additional amino acids (Glu, Phe); however, these amino acids cannot be phosphorylated. The orientation of the subcloned EcoRI fragment was analyzed by PCR using the primers PS-2 $\mathrm{N}^{\prime}$ forward and PS-1 1660 reverse. The second hybrid construct was generated using the same strategy. The following primers were used to amplify the PS-1 N terminus: 5'-CCGAATTC GGCGCCATATTTCAATGT-3' (PS-1 N' reverse), 5' -CCGAATTCAAGAAAGAACCTCAA-3' (PS-1 187 forward). The following primers were used to amplify the PS-2 sequence between TMl and the stop codon: 5'-CCGGATCCACACCATGTCC CTCA-3' (PS-2 1700 reverse), 5' -CCGAATTCAA GCACGTGATCATGCTG-3' (PS-2 TMl forward).

The double serine mutations at position 7 and 9 of PS- 2 were generated by PCR using the following forward primer: 5'-CCGAATTCCTTCC AGAGGCAGGGCTATGCTCACATTCATGGCCG CCGACGCCGAGGAA-3' (PS-2Ser7,9Ala forward) and the PS-2 1700 reverse primer (see above). The construct was subcloned into the EcoRI and BamHI restriction sites of pSG5. The mutations were confirmed by DNA sequencing.

The PS- $2 \Delta$ as (acidic stretch) cDNA construct was generated by PCR using the following primers: 5'-CCGAATTCCTTCCAGAGGCAGGGCTAT GTCGGCCGAGAGC-3' (PS-2 $\Delta$ as forward) and PS-2 1700 reverse (see above). The PCR products were cloned into the EcoRI and BamHI restriction sites of pSG5.

PS-2 GST fusion proteins were generated as follows: A fusion protein of glutathione S-transferase (GST) and the $\mathrm{N}$ terminus of PS-2 was constructed by using the primers 5 '-CCGGATC CCTCACATTCATGGCC-3' and 5'-TGCGGTCGA CGTGCTTCGCTCCGTA- $3^{\prime}$ to generate the coding region of the PS- $2 \mathrm{~N}$ terminus with PCR. The fragments were inserted in the EcoRI/SalI sites of pGEX-4T-1 (Pharmacia). The fusion proteins were expressed in Escherichia coli $\mathrm{DH} 5 \alpha$ and pu- rified on glutathione Sepharose-4B (Pharmacia, Uppsala, Sweden) according to the supplier instruction.

COS-7 cells, CHO cells, and kidney 293 cells were transfected using DOTAP (BoehringerMannheim, Indianapolis, IN, U.S.A.) as described by the manufacturer.

\section{Immunocytochemistry}

Immunocytochemical experiments were carried out as described (32) with a Leitz DMRBE microscope. Images were taken at a magnification of $1000 \times(100 \times / 10 \times)$.

\section{Confocal Laser Scanning Microscopy}

CHO cells stained with antibodies TOR 519 and a monoclonal antibody to grp78 (BiP; StressGen) were analyzed with a BioRad MRC-1024 confocal laser scanning imaging system connected to a Nikon Diaphot 300 inverted microscope. The light source was an argon-krypton laser. Confocal images were collected at the excitation wavelengths of 488 and $568 \mathrm{~nm}$ (green fluorescence for detection of PS proteins and red fluorescence for the detection of grp78 [BiP]).

\section{Antibodies}

The following polyclonal antisera were used for this study (see also Fig. 1 below): TOR519 raised to PS- $1_{109-120}$, BOS4627 raised to PS- $1_{457-467}$, and BOS4624 raised to PS- $1_{343-357}$. The respective peptides were covalently linked to keyhole limpet haemocyanin via a C-terminal cystein residue or were conjugated to rabbit serum albumin and inoculated into rabbits. Antisera from individual rabbits were pooled, and IgG was precipitated with ammonium sulfate. For immunocytochemical experiments, antibody TOR519 was affinity purified using Sulfo-link agarose (Pierce, Rockford, IL, U.S.A.) coupled with the appropriate peptide. Antibody TOR519 and BOS4627 recognize PS-1 as well as PS-2. Antibody BOS4624 selectively identifies PS-1 (Fig. $1 \mathrm{~B}$ and C). $\beta$ APP from cell lysates was immunoprecipitated using antibody $\mathrm{C} 7$ raised to its $20 \mathrm{C}$-terminal amino acids (33) and secreted $\mathrm{APP}_{\mathrm{s}}$ from conditioned media was immunoprecipitated with antibody B5 (15). The monoclonal antibodies $5 \mathrm{~A} 3 / 1 \mathrm{G} 7$ (35) to the ectodomain of $\beta$ APP were used to detect $\beta$ APP by immunocytochemistry. Antibodies against the Golgi protein p58, and lectin from Triticum vulgaris (wheat germ agglutinin; WGA) labeled with TRITC were obtained from Sigma (St. Louis, MO, U.S.A.). 


\section{Metabolic Labeling and Immunoprecipitation}

Metabolic labeling and immunoprecipitations were carried out as described by Haass et al. (34) except that the immunoprecipitates were heated to $68^{\circ} \mathrm{C}$. Immunoprecipitates were separated on $8 \%$ or $10 \%$ SDS polyacrylamid gels containing $4 \mathrm{M}$ urea.

\section{Deglycosylation Experiments}

To inhibit posttranslational $\mathrm{N}$-linked glycosylation, transfected COS-7 cells were metabolically labeled with $\left[{ }^{35} \mathrm{~S}\right]$-methionine in the presence of $10 \mu \mathrm{g} / \mathrm{ml}$ tunicamycin (Sigma). In parallel experiments immunoprecipitated proteins were incubated for $16 \mathrm{hr}$ at $37^{\circ} \mathrm{C}$ with 2 units of $\mathrm{N}$-glycosidase $\mathrm{F}$ (Boehringer Mannheim) according to the suppliers instruction.

\section{Pulse Chase Experiments}

PS-1/PS-2 transfected COS-7 cells or CHO cells, were pulse labeled with $\left[{ }^{35} \mathrm{~S}\right]$-methionine for 25 min and chased in the presence of excess amounts of unlabeled methionine for the indicated time points. Cell lysates were prepared and immunoprecipitated as described above using antibody BOS4627.

\section{In Vivo Phosphorylation and Sulfation}

A confluent cell monolayer, transiently transfected with PS- 1 or PS-2 cDNAs, was incubated for 45 min in phosphate-free (Sigma) or sulfate-free (Gibco-BRL, Gaithersburg, MD, U.S.A.) media, respectively. The media were aspirated and the respective fresh media were added, together with 13-36 MBq $\left[{ }^{32} \mathrm{P}\right]$-orthophosphate or $\left[{ }^{35} \mathrm{~S}\right]$-sulfate, and cells were incubated for $2-4 \mathrm{hr}$ at $37^{\circ} \mathrm{C}$. The conditioned media were then aspirated, and cells were washed twice with ice-cold phosphatebuffered saline (PBS) and immediately lysed on ice with lysis buffer containing $1 \% \mathrm{NP}-40$ for $10 \mathrm{~min}$. Cell lysates were centrifuged $10 \mathrm{~min}$ at $14,000 \times$ $g$, and supernatants immunoprecipitated with specific anti-PS antibodies for 2-3 hr. Radiolabeled proteins were separated by SDS-PAGE as described above and visualized by autoradiography. Quantitations were done by phospohor-imaging (Molecular Dynamics Sunnyvale, CA, U.S.A.) using the ImageQuant program as described by Hung et al. (35).
To stimulate protein kinase $\mathrm{C}$ activity during in vivo labeling with $\left[{ }^{32} \mathrm{P}\right]$-orthophosphate, phosphorylation was carried out in the presence of $1 \mu \mathrm{M}$ phorbol 12,13-dibutyrate (PDBu). To inhibit protein kinase $C$ activity, the specific inhibitor GF 109203X (Biomol; final concentration 0.1 $\mu \mathrm{M}$ ) was added to the media during periods of labeling.

In vitro phosphorylation of fusion proteins was carried out in phosphorylation buffer $(50 \mathrm{mM}$ Tris, $\mathrm{pH} 7.4 / 10 \mathrm{mM} \mathrm{MgCl}_{2} / 5 \mathrm{mM}$ DTT) in a volume of $50 \mu \mathrm{l}$ containing $30 \mathrm{ng} \mathrm{CK}-1$ (New England Biolabs Beverly, MA, U.S.A.) and CK-2, respectively and $1 \mu \mathrm{g}$ protein substrate. The reaction was started by addition of $10 \mu \mathrm{M}\left[\gamma^{32} \mathrm{P}\right]$-ATP and terminated after 15 min with SDS-sample buffer. Rabiolabeled proteins were analyzed by SDS-PAGE and autoradiography.

\section{Phosphoamino Acid Analysis}

$\left[{ }^{32} \mathrm{P}\right]$-labeled PS-2 was isolated by immunoprecipitation, separated by SDS-PAGE, electrotransfered onto PVDF-membrane and localized by autoradiography. Bands were cut out and 2D-phosphoamino acid analyses was carried out according to Boyle et al. (36). Briefly, PS-2 proteins were hydrolyzed by incubation in $6 \mathrm{~N} \mathrm{HCl}$ for 90 min at $110^{\circ} \mathrm{C}$. Supernatants were dried in a SpeedVac concentrator, and the resulting pellets dissolved in $\mathrm{pH} 1.9$ buffer $(7.8 \%$ acetic acid/ $2.5 \%$ formic acid) and spotted onto cellulose-TLC plates together with unlabeled phosphoamino acids (P-Ser, P-Thr, P-Tyr; $1 \mu$ g each). High voltage electrophoresis was carried out for $20 \mathrm{~min}$ (pH 1.9 buffer) at $1.5 \mathrm{kV}$ and for $16 \mathrm{~min}(\mathrm{pH} 3.5$ buffer; $5 \%$ acetic acid $/ 0.5 \%$ pyridine) at $1.3 \mathrm{kV}$, respectively. Radioactive phosphoamino acids were identified by autoradiography and comparison with ninhydrin-stained standards.

\section{RESULTS}

\section{Antibody Specificity and Expression of PS Proteins}

To test the specificity of the anti-PS antibodies, COS-7 cells were transiently transfected with the PS- 1 or PS- 2 cDNA and metabolically labeled with $\left[{ }^{35} \mathrm{~S}\right]$-methionine. Cell lysates were immunoprecipitated with antibodies raised to PS-1 (TOR519, BOS4627, BOS4624; Fig. 1A). As shown in Fig. 1 B and C, PS-1 as well as PS-2 were expressed as proteins with an apparent molecu- 
lar weight of approximately $45 \mathrm{kD}$. As expected from sequence homologies between PS-1 and PS-2, antibodies TOR519 and BOS4627 specifically immunoprecipitate both proteins, whereas antibody BOS4624 exclusively identifies PS-1 (Fig. $1 \mathrm{~B}$ and C). No reactivity was observed in mock transfected cells using antibody TOR519 (Fig. 1B). In addition to these low-molecular weight proteins, proteins of $\sim 90 \mathrm{kD}$ were found. After longer exposure, $\sim 140-\mathrm{kD}$ proteins are also observed. This observation suggests that PS proteins might form dimeric and trimeric aggregates. The high-molecular weight bands of the PS proteins are indeed aggregates and not coprecipitating or nonspecifically precipitated proteins as shown by an expected shift of the predicted molecular weight of these multimeric species in cells expressing various $\mathrm{C}$-terminally truncated PS-1 proteins terminating after TM7, TM6, TM5, and TM4 (Fig. 1D; for details, see below). However, it is not clear yet if these multimeric forms occur in vivo or are a result of the extraction procedure (see discussion).

Sequential deletion of the $\mathrm{C}$ terminus removes the epitopes of the corresponding antibody, and results in the failure to detect these proteins. The N-terminal antibody TOR519 identifies all deletions (Fig. 1D), whereas the loopspecific antibody BOS4624 identifies full-length and TM7-deleted PS-1 but not the truncated PS-1 protein terminating after TM6 (Fig. 1E). Moreover, the C-terminal antibody BOS4627 immunoprecipitates full-length PS-1 only, and none of the deleted PS proteins are recognized (Fig. 1E). Therefore, these results clearly demonstrate the specificity of the antibodies used and show that both antibodies, TOR519 and BOS4627 can be used for specific detection of PS- 1 and PS-2, whereas antibody BOS4624 detects exclusively PS-1 proteins.

\section{Subcellular Localization of PS Proteins}

To investigate the subcellular localization of endogenous PS proteins, confocal laser scanning microscopy was carried out. Untransfected $\mathrm{CHO}$ cells were stained with the affinity-purified antibody TOR519. A diffuse staining throughout the cytoplasm was detected (Fig. 2A). Since the staining pattern suggested that PS proteins might be located within the ER, we double-stained the CHO cells with an antibody to the ER-located protein grp78 (BiP) (Fig. 2B), which resulted in a highly similar staining pattern. An almost com- plete colocalization was observed for PS proteins and grp78 (BiP) after superimposing the images obtained in Fig. 2 A and B (Fig. 2C). To prove the specificity of the observed staining pattern, antibody TOR519 was preabsorbed with the corresponding peptide antigen. Preabsorption clearly abolished the ER staining (compare Fig. $2 \mathrm{D}$ and E). No staining was observed as well, when secondary antibodies were used as a negative control (Fig. 2F). Moreover, the independent antibody BOS4627 to the C terminus of PS- 1 also stained the ER (data not shown). These results therefore indicate that endogenous PS proteins are localized predominantly within the ER.

To prove the subcellular localization of PS proteins more precisely, PS-1 as well as PS-2 proteins were overexpressed in COS-7 cells. PS-1 was observed by immunostaining with antibody BOS4627 within a network throughout the cytoplasm, which colocalized with the ER marker grp78 (BiP) (Fig. $3 \mathrm{~A}$ and B). Since the experiments were carried out with transiently transfected cells, a large number of untransfected cells were observed, which were stained very weakly, showing the specifity of the antibody used. In order to prove if PS proteins can also be detected within Golgi compartments, PS-1-transfected cells were double stained with a PS antibody and an antibody to the Golgi protein p58. Indeed, PS- 1 could be detected within the Golgi stack as indicated by costaining of antibody BOS4627 to PS- 1 and the antibody to the Golgi protein $\mathrm{p} 58$ (Fig. $3 \mathrm{C}$ and D). However, it should be noted that the majority of PS-1 proteins are localized in the ER, which is out of focus in Fig. $3 \mathrm{C}$ and D. Since $\beta A P P$ is predominantly located within the Golgi (37) we proved a potential colocalization of PS- 1 and $\beta$ APP. COS-7 cells, double-transfected with the $\beta$ APP and PS-1 CDNA, were doublestained with BOS4627 and the monoclonal antibody $5 A 3 / 1 G 7$ to $\beta A P P$ (38). As shown in Fig. $3 \mathrm{E}$ and F, colocalization of PS- 1 and $\beta$ APP could be observed. Interestingly, the colocalization was restricted to the Golgi, the predominant subcellular localization of $\beta$ APP (37), whereas very little costaining was observed within the ER. This suggests that PS proteins, in contrast to $\beta$ APP, are probably actively retained within the ER. Moreover, since $\beta A P P$ is detected at its expected subcellular localization, overexpression of PS-1 is unlikely to result in an artificial protein retention within the ER. If that would be the case $\beta A P P$ should also be retained and predominantly locate within the ER, which was not observed. Data similar to those shown in Fig. 3 were ob- 
A
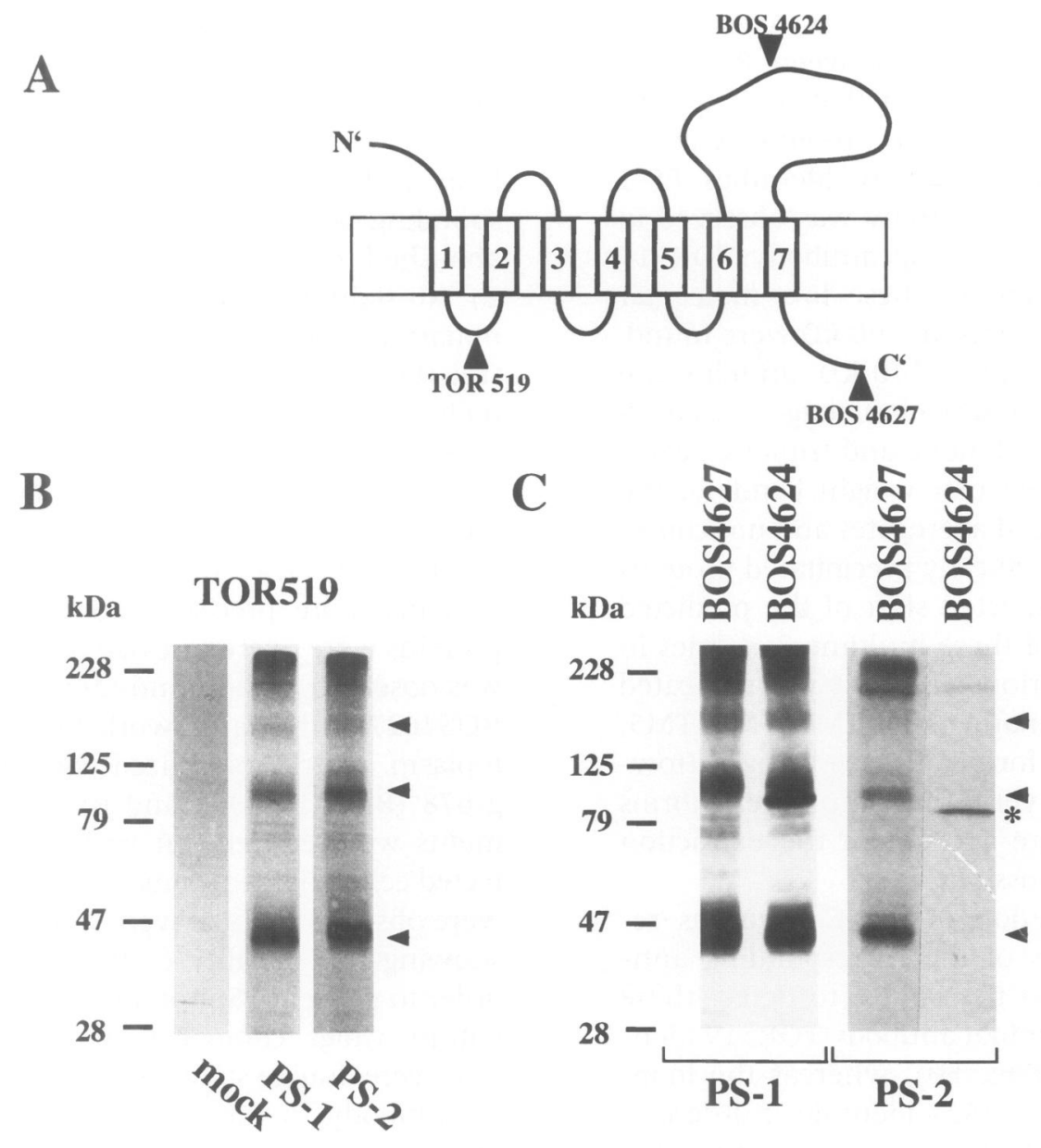

D

$\mathbf{E}$

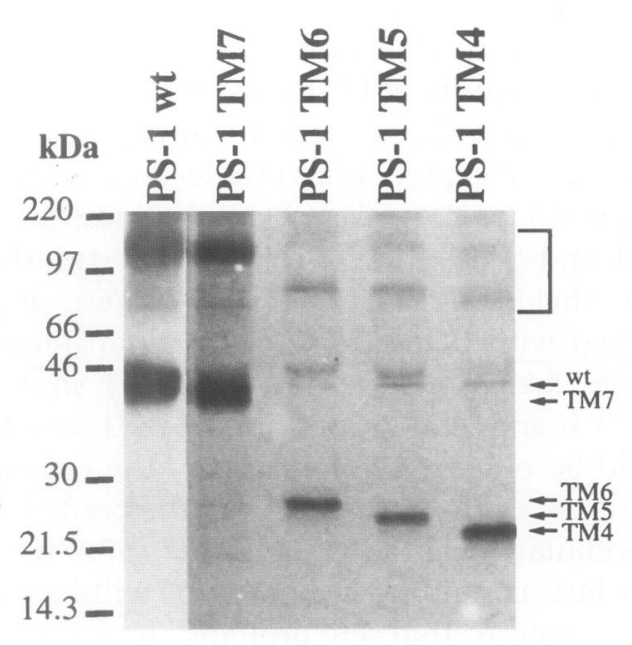

TOR519

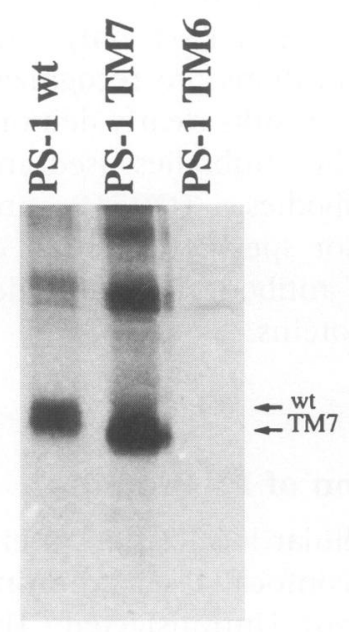

BOS 4624

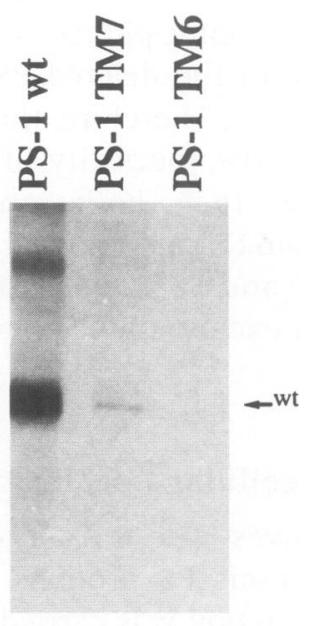

BOS 4627

tained for PS-2, indicating that both proteins show a similar subcellular localization (see Fig. 4 below and data not shown).

In order to prove if ER retention signals are

present within the PS amino acid sequence, the subcellular localization of truncated forms of PS-2 ending after TM4 (Fig. 4F) was investigated using the affinity purified antibody TOR519. 
FIG. 1. Antibody specificity and cellular expression of PS proteins in transfected COS-7 cells

(A) Schematic representation of the putative seven transmembrane domain structure of PS proteins. The epitopes and names of the PS antibodies used are indicated. (B) Immunoprecipitations with antibody TOR519 of cell lysates of COS-7 cells mock-transfected or transfected with the PS-1 or PS-2 cDNA. Note the strong augmentation of polypeptides with a molecular weight of $\sim 45, \sim 90$, and $\sim 180 \mathrm{kD}$ (indicated by arrowheads) in PS-1- or PS-2transfected cells. Antibody TOR519 immunoprecipitates PS-1 and PS-2 proteins. (C) Immunoprecipitations of PS-1 and PS-2 from cell lysates of PS-1- and PS-2-transfected COS cells with antibodies BOS4627 and BOS4624. Note that antibody BOS4627 specifically immunoprecipitates PS-1 and PS-2 proteins whereas antibody BOS4624 selectively identifies PS-1 proteins. *A nonspecific polypeptide immunoprecipitated by BOS4624. Arrowheads indicate the putative PS monomers and oligomers. (D) C-terminal deletions of PS-1 result in a shift of the high-molecular weight proteins described in Panels B and C. Stop codons were introduced after TM7, TM6, TM5, and TM4. COS-7 cells transfected with the corresponding cDNA constructs were metabolically labeled and immunoprecipitated with antibody TOR519. Note the shift of the $45-\mathrm{kD}$ as well as the high-molecular weight proteins, clearly indicating that these represent PS dimers and higher multimers (multimers are indicated by the bracket). (E) The introduction of stop codons after TM6 and TM7 removes the epitopes of the corresponding antibodies. COS-7 cells were transfected with the wt PS-1 cDNA or with PS-1 cDNA constructs containing stop codons inserted after TM6 and TM7. After metabolic labeling, cell lysates were immunoprecipitated with antibodies BOS4624 or BOS4627. Note the loss of the immunoreactivity of the corresponding antibodies after removal of the epitope, which clearly indicates the specificity of the antibodies used.

A

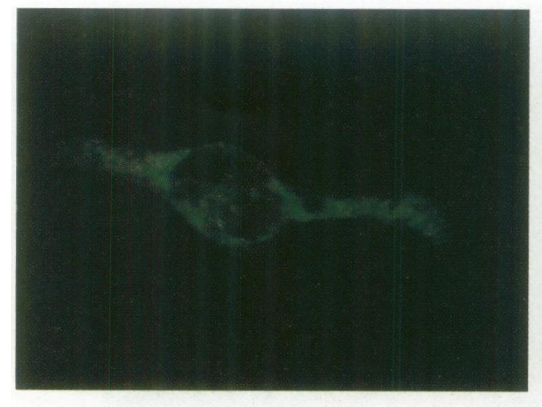

B

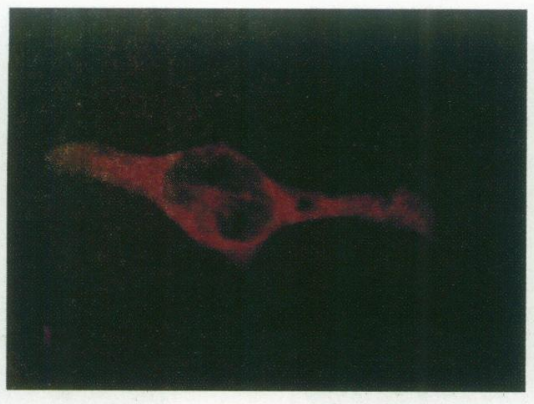

C PS \& ER

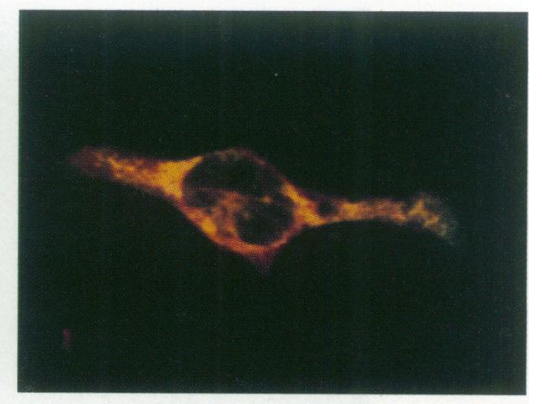

$\mathbf{D}$

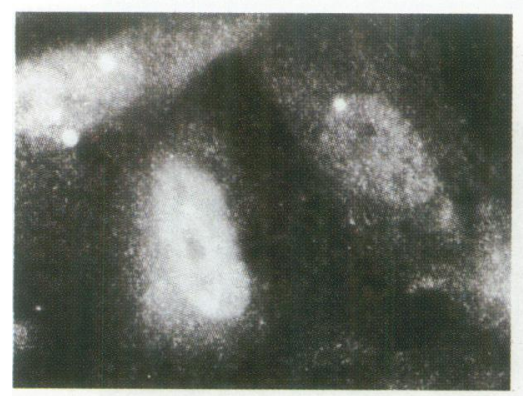

E preabsorption

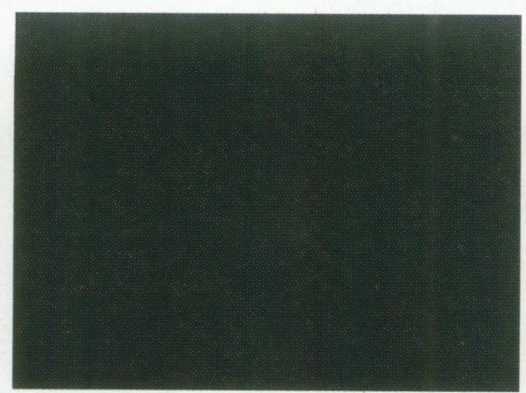

F sec. Ab. control

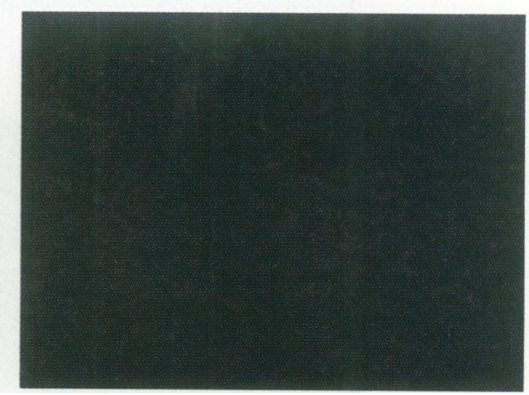

FIG. 2. Subcellular localization of endogenous PS proteins in CHO cells analyzed by confocal microscopy

Endogenous PS proteins expressed in CHO cells (PS) were detected with the affinity-purified antibody TOR519 (A, PS). Double labeling with antibody TOR519 (A, PS) and a monoclonal antibody to grp78 (BiP) revealed a highly similar staining (B, ER). Superimposing the images obtained in Panels A and B reveals an almost complete overlapping staining pattern (C, ER \& PS) indicating that endogenous PS proteins are located within the ER. (D and E) CHO cells were stained with the affinity purified antibody TOR519 (D) or with TOR519 preabsorbed with the corresponding peptide antigen and analyzed by light microscopy (E). Preabsorption of TOR519 clearly inhibits the staining pattern observed in Panel D. (F) CHO cells stained with the secondary antibody alone. Note, that PS proteins were detected within the nuclear envelope but not within the nucleus (compare the confocal image in Panel A and the light microscopy photograph in Panel D). 
A

PS-1

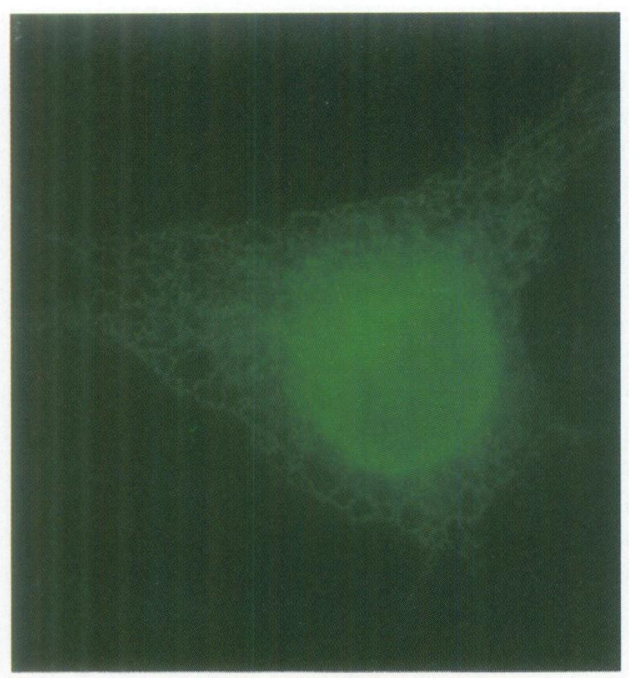

C

PS-1

E

PS-1

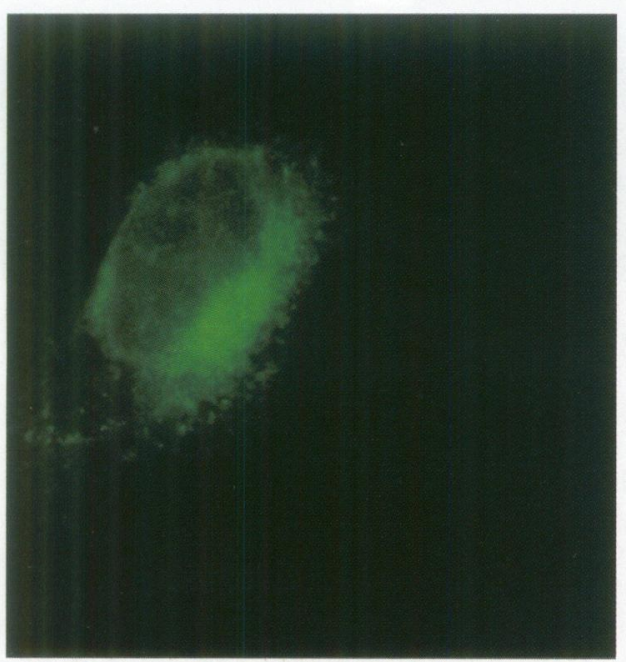

B

ER

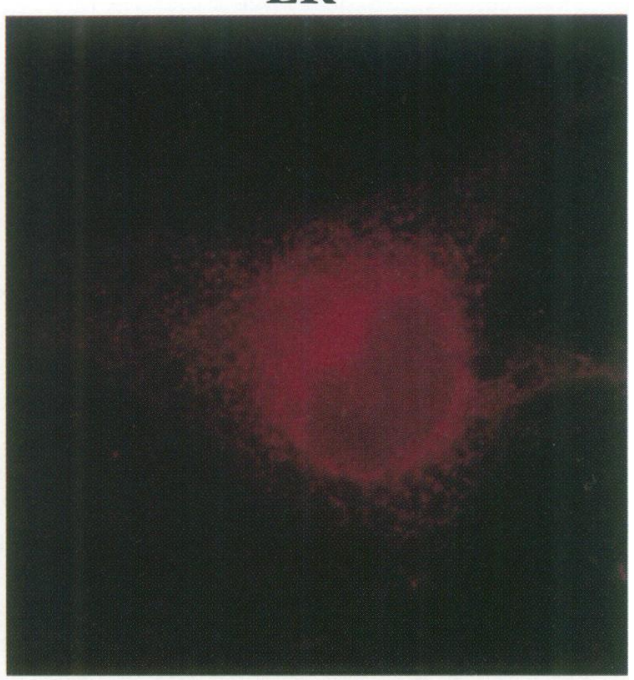

D

Golgi

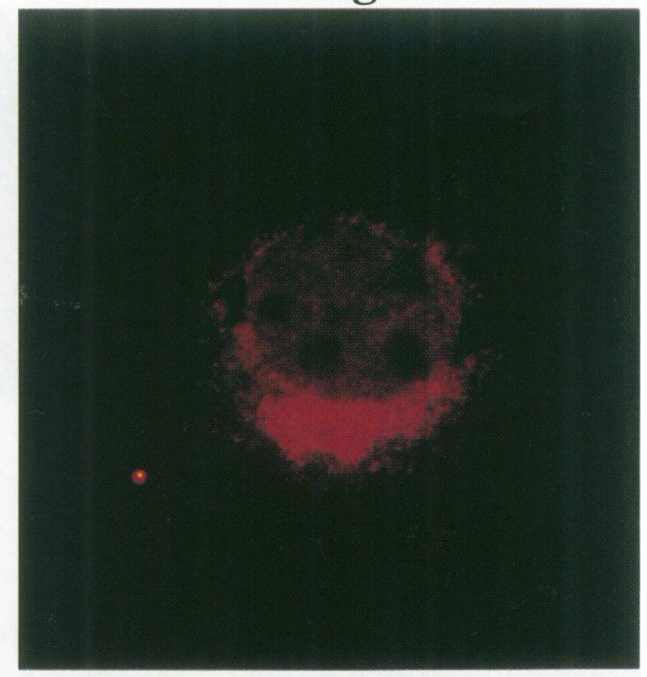

F

BAPP 
Full-length PS-2 (Fig. 4A) is detected predominantly within reticulate structures throughout the cytoplasm (Fig. 4B). These structures were identified by costaining with an antibody against grp78 (BiP) as ER (Fig. 4C). Again, full-length PS-2 was also detected in the Golgi as shown by costaining with WGA (Fig. $4 \mathrm{D}$ and E). Interestingly, the C-terminal deleted form of PS-2 ending after TM4 shows a similar staining pattern like full-length PS-2 (Fig. 4 F-K). No differences in ER/Golgi distribution of full-length PS-2, and its truncated derivatives were observed. Analogous results were obtained with PS-2 proteins ending after TM7, TM6, and TM5, respectively (data not shown), indicating that ER retention signals are not present between TM4 and the C terminus. These data might therefore suggest that intramolecular aggregation of PS proteins is sufficient for their ER retention (see discussion). Similar data were obtained for the corresponding deleted forms of PS-1 (data not shown).

\section{Lack of Sulfation and Maturation of PS Proteins Is Consistent with Predominant Localization of PS Proteins within the Endoplasmic Reticulum}

In order to determine whether PS proteins are modified by sulfation, which might indicate transport to late Golgi compartments (39), COS-7 cells transfected with the PS-1 or PS-2 cDNA, were labeled in vivo with either $\left[{ }^{35} \mathrm{~S}\right]$-sulfate or $\left[{ }^{35} \mathrm{~S}\right]$ methionine. Cell lysates were prepared and immunoprecipitated with antibody BOS4627. Although both PS- 1 and PS- 2 were expressed in COS-7 cells, as shown by $\left[{ }^{35} \mathrm{~S}\right]$-methionine labeling, no signal could be detected for $\left[{ }^{35} \mathrm{~S}\right]$-sulfate-labeled cells (Fig. 5A). As a positive control $\beta$ APP was isolated under identical conditions. Precipitation of cell lysates with an antibody to the $C$ terminus of $\beta A P P$ revealed high amounts of sulfated, mature fulllength $\beta A P P$, which is consistent with data pub- lished previously (40). These data indicate that PS proteins do not undergo protein sulfation in transiently transfected cells. To assess posttranslational maturation of PS proteins, we performed pulsechase experiments. COS-7 cells transfected with the PS-1 or PS- 2 cDNA were pulse-labeled for 25 min and chased in the presence of excess amounts of unlabeled methionine up to $22 \mathrm{hr}$. PS proteins appear to be stable over several hours (Fig. 5B). Similar results were obtained using PS-1 or PS- 2 transfected CHO cells (data not shown). A precise determination of the half-life time of PS proteins is not possible, because all experiments were performed on transient transfected cells. No shift in the molecular weights of the PS- 1 or PS- 2 proteins could be detected during the chase (Fig. 5B), suggesting that PS proteins are not modified by posttranslational glycosylation. The lack of sulfation and maturation is consistent with the localization of PS proteins within the ER (Figs. 2 and 3), since both posttranslational modification are expected to occur in late Golgi compartments (39).

The potential lack of glycosylation was further proved by treating PS-transfected cells with tunicamycin. No change in the molecular weight of PS proteins was observed after tunicamycin treatment, although endogenous $\mathrm{APP}_{\mathrm{S}}$ immunoprecipitated from the conditioned media of the same cells showed the expected shift in the molecular weight by approximately $2 \mathrm{kD}$ (40) (Fig. 5C), indicating that glycosylation of $\beta$ APP was indeed inhibited by tunicamycin treatment. In addition, immunoprecipitated PS proteins from cell lysates and $\mathrm{APP}_{\mathrm{S}}$ from conditioned media were incubated with $\mathrm{N}$-glycosidase F. No molecular weight shift was observed for either PS-1 or PS-2, while $\mathrm{APP}_{\mathrm{s}}$ showed the expected reduction of the molecular weight after $\mathrm{N}$-glycosidase $\mathrm{F}$ treatment (40) (Fig. 5D). These data therefore indicate that PS proteins do not undergo $\mathrm{N}$-linked glycosylation.

\section{FIG. 3. Subcellular localization of overexpressed PS-1 in COS-7 cells}

COS-7 cells were transfected with the PS-1 cDNA and co-stained with antibody BOS4627 (A, PS-1) and a monoclonal antibody to grp78 (BiP), labeling the ER (B, ER). The majority of PS-1 staining was observed within the ER as indicated by the overlapping staining of antibody BOS4627 and the antibody to grp78 (BiP). (C and D). COS-7 cells transfected with the PS-1 cDNA were costained with BOS4627 (C, PS-1) and a monoclonal antibody to p58 (D, Golgi) which is located within the Golgi. Overlapping expression of p58 and PS-1 is observed to some extend within the Golgi. Note that the photograph was taken by focusing on the Golgi. The predominant ER staining with antibody BOS4627 is out of focus. (E and F) Colocalization of PS- 1 and BAPP. COS-7 cells were double transfected the PS- 1 cDNA and the $\beta$ APP cDNA CMV695 (38) and stained with BOS4627 (E, PS-1) and the monoclonal antibody 5A3/1G7 to $\beta$ APP (F, $\beta A P P$ ). Note the overlapping staining of PS- 1 and $\beta A P P$ within the Golgi. The photograph focuses on the Golgi, the predominant ER staining of antibody BOS4627 is out of focus. 
A

FIG. 4. Cellular localization of full-length PS-2 (A) and the Cterminal truncated derivative ending after TM4 (F) in COS-7 cells transfected with the corresponding cDNAs

Cells were double immunostained using the affinity purified antibody TOR519 (B and G) and with antibodies against grp78 (BiP; $\mathrm{C}$ and $\mathrm{H}$ ) to detect the ER or with WGA to detect the Golgi compartment (50) (D, E, I, and $\mathrm{K})$. No major differences were observed in the cellular localization of truncated PS-2 TM4 proteins as compared to full-length PS-2. Wt and recombinant PS- 2 proteins are predominantly located within ER and to a smaller extent in the Golgi, as shown above (Fig. 3). Note, that cells transfected with the deletion construct did not react with antibody BOS4627 (data not shown), which clearly shows the specificity of the antibodies used. Moreover, antibody TOR519 strongly detects a few transfected cells while the majority of the (untransfected) cells is stained only very weakly, again strongly supporting the antibody specificity. The Golgi is marked by arrowheads in Panels D and $\mathrm{E}$ as well as in Panels I and K.
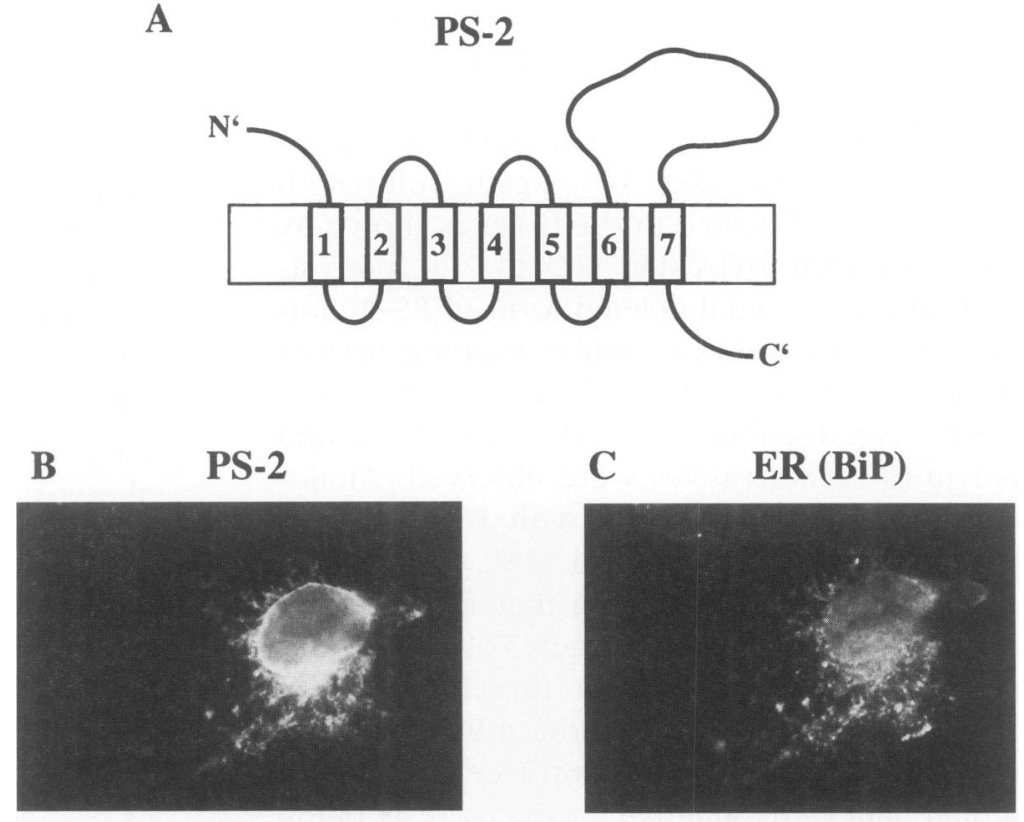

D

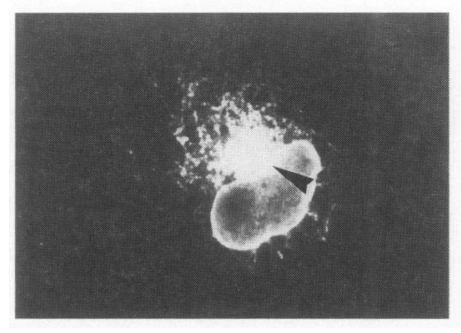

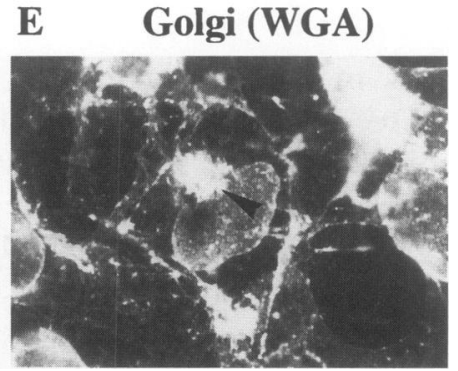

\section{Selective Phosphorylation of the PS-2 Protein}

Since the biological activity of many receptor like proteins with a seven TM domain structure such as the glutamate receptor appear to be regulated by protein phosphorylation (41), in vivo phosphorylation of PS proteins was analyzed. COS-7 cells transfected with the PS-1 and PS-2 cDNA were metabolically labeled with $\left[{ }^{32} \mathrm{P}\right]$-orthophosphate or $\left[{ }^{35} \mathrm{~S}\right]$-methionine. As described above, monomeric as well as dimeric forms of $\left[{ }^{35} \mathrm{~S}\right]-\mathrm{me}$ thionine-labeled PS proteins were observed (Fig. 6A). Interestingly, after in vivo labeling with $\left[{ }^{32} \mathrm{P}\right]$-orthophosphate we detected phosphate-labeled PS-2 proteins of both monomeric and dimeric forms (Fig. 6A). In contrast, almost no phosphate incorporation (only visible on overexposed autoradiogramms) into the PS-1 protein was observed (Fig. 6A), although similar expression levels of PS- 1 and PS- 2 were obtained as judged by $\left[{ }^{35} \mathrm{~S}\right]$-methionine labeling. As determined by phos- phor-imaging, phosphate incorporation into PS-1 was approximately $5-10 \%$ compared with that in PS-2 (data not shown). In order to assess whether FAD mutations within PS- 1 or PS- 2 influence their phosphorylation status, we transfected COS-7 cells with the PS-1 cDNA containing the Ala246Glu mutation (FAD l [17]) and with the PS-2 cDNA containing the Asn141Ile mutation found in the Volga German kindred $(18,19)$. As shown for wildtype PS-2, the Asnl41Ile mutation is strongly phosphorylated, whereas very little phophorylation for the Ala246Glu mutation (PS-1) was observed (Fig. 6B).

To determine which amino acids of the PS-2 proteins are modified by protein phosphorylation, phosphoamino acid analysis of in vivo phosphorylated PS-2 proteins was performed. As shown in Fig. 6C, PS-2 proteins are phosphorylated exclusively on serine residues. To demonstrate that PS-2 phosphorylation is a general phenomenon not restricted to COS-7 cells, PS-2 
F

PS-2 TM4
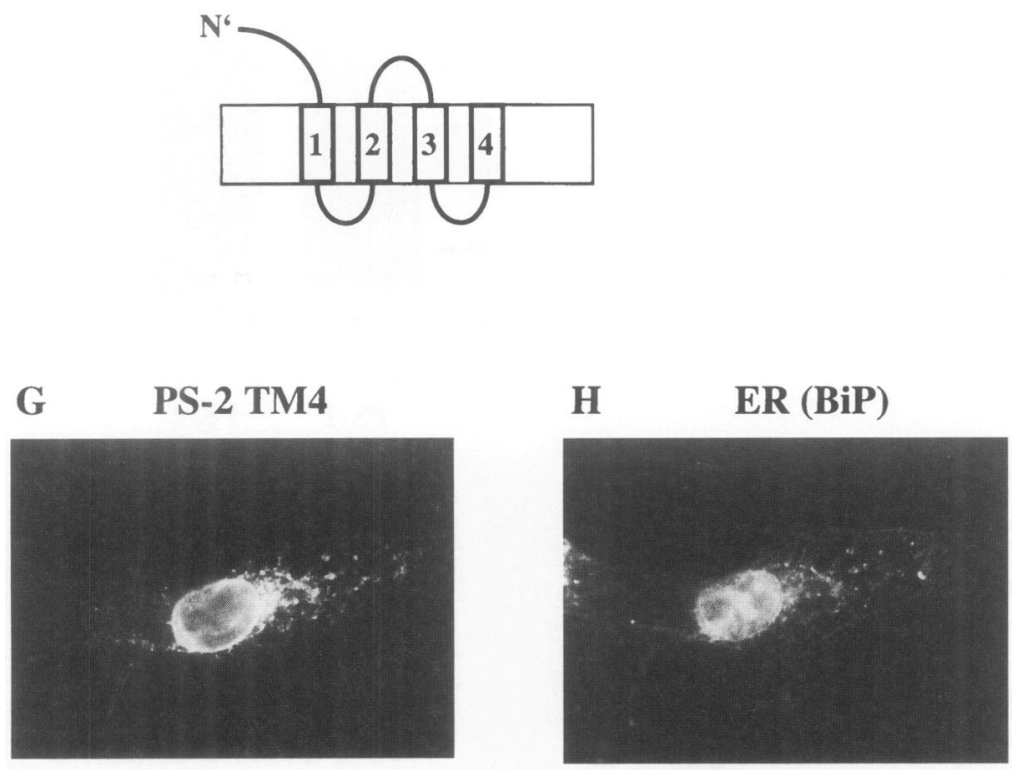

I

PS-2 TM4

K Golgi (WGA)
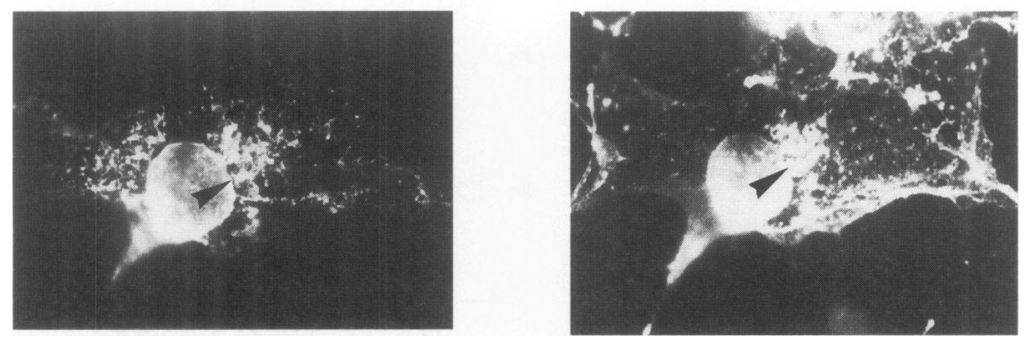

FIG. 4. (Continued)

phosphorylation was also analyzed in transfected $\mathrm{CHO}$ and human kidney 293 cells. Again, monomeric and dimeric forms of PS-2 proteins were detected after labeling with $\left[{ }^{35} \mathrm{~S}\right]$-methionine (Fig. 6D). As observed in transfected COS-7 cells, PS-2 was also phosphorylated in both, human kidney 293 cells and CHO cells (Fig. 6D). Taken together, these data demonstrate selective phosphorylation of the PS-2 protein, which occurs exclusively on serine residues, whereas very little phosphorylation of the PS-1 protein can be detected.

\section{Protein Kinase C Is Not Involved in Phosphorylation of PS-2}

The amino acid sequence of PS proteins contains several potential substrate recognition sequences for protein kinase C (PKC) (17-19). To determine if PS-2 proteins are phosphorylated by
PKC, COS- 7 cells transfected with the PS- 2 cDNA were treated with phorbol 12,13-dibutyrate $(\mathrm{PDBu})$ as described previously $(42)$ or with a specific PKC-inhibitor (GF109203X) during labeling with $\left[{ }^{32} \mathrm{P}\right]$-orthophosphate. However, neither activation of PKC by PDBu nor inhibition by GF109203X did alter the phosphorylation of PS-2 (Fig. 7). It should be noted that treatment with PDBu or GF109203X did not alter the expression of PS-2 proteins, as proven in multiple experiments using transfected COS-7 cells labeled with $\left[{ }^{35} \mathrm{~S}\right]$-methionine. In addition, activation of PKC was monitored by analysis of soluble $\beta A P P$ in conditioned media under similar conditions. As reported by Buxbaum et al. (42), treatment with PDBu did increase the amount of soluble $\beta$ APP released into the conditioned media, indicating that PKC was activated under the experimental conditions used in the above described experiments (data not shown). 
A

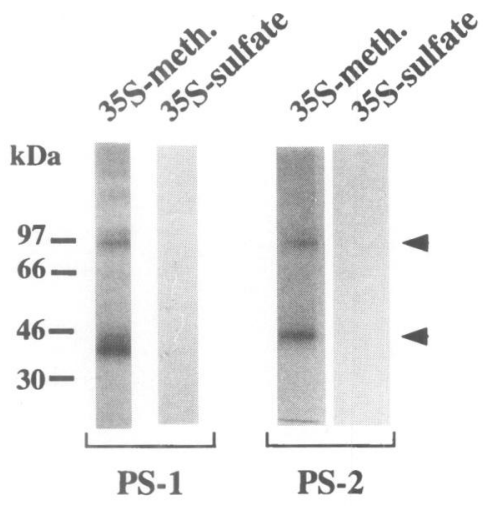

B

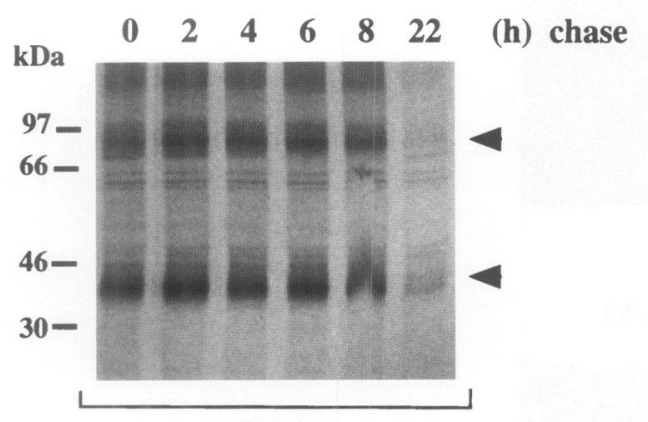

PS-1

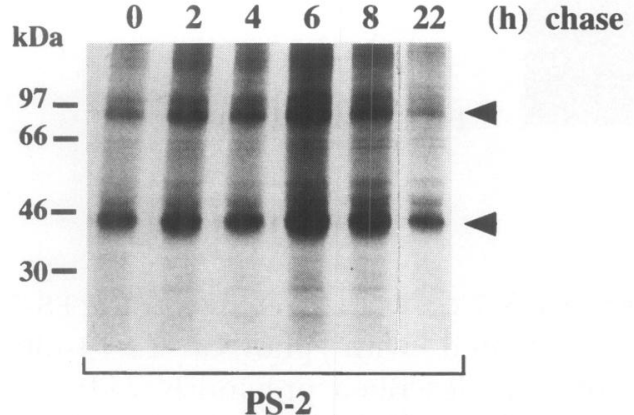

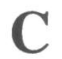

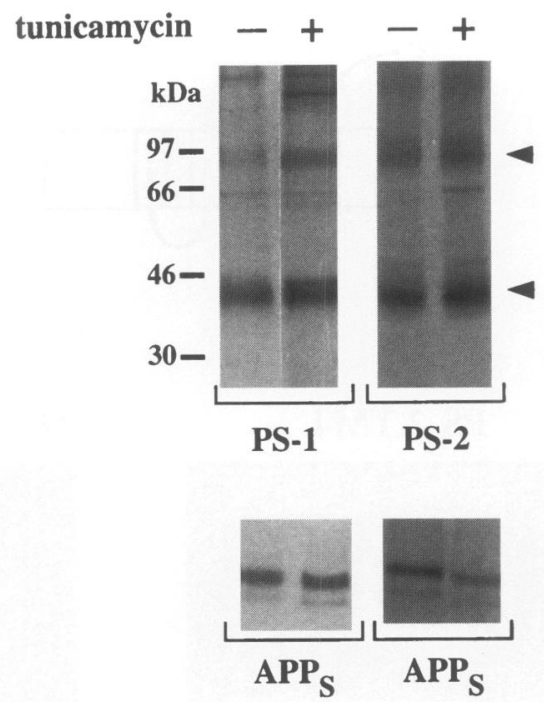

D

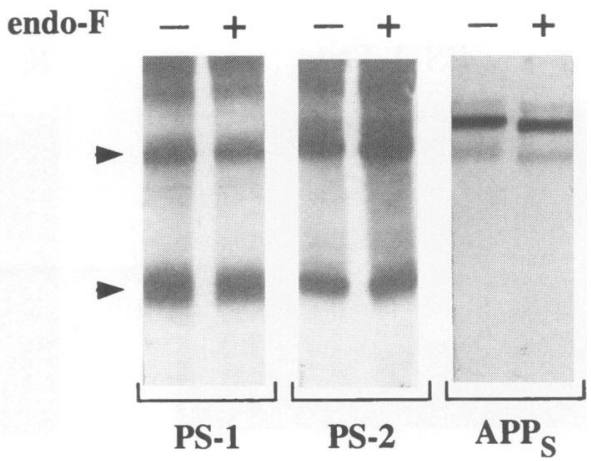

FIG. 5. Posttranslational modifications of PS protein

(A) PS proteins are not sulfated. COS-7 cells transfected with the PS-1 or PS-2 CDNA were labeled with either $\left[{ }^{35} \mathrm{~S}\right]$-methionine $\left(\left[{ }^{35} \mathrm{~S}\right]\right.$-meth.) or $\left[{ }^{35} \mathrm{~S}\right]$-sulfate and immunoprecipitated with antibody BOS4627. Arrowheads indicate the putative PS monomers and dimers. Oligomers of higher molecular weight were revealed after longer exposure. (B) Pulse-chase experiment. COS-7 cells transfected with the PS-1 (upper panel) or PS-2 (lower panel) cDNA were pulse-labeled with $\left.{ }^{35} \mathrm{~S}\right]$-methionine for $25 \mathrm{~min}$ and chased in the presence of excess amounts of unlabeled methionine for the time periods indicated. Cell lysates were immunoprecipitated with antibody BOS4627. Arrowheads indicate the putative PS monomers and dimers. Oligomers of higher molecular weight were revealed after longer exposure. (C) Treatment of cells with tunicamycin. COS-7 cells transfected with PS-1 or PS-2 cDNA were labeled for $3 \mathrm{hr}$ with [ $\left.{ }^{35} \mathrm{~S}\right]$-methionine in absence or presence of $10 \mu \mathrm{g} / \mathrm{ml}$ tunicamycin. PS proteins were immunoprecipitated from cell lysates with antibody BOS4627 and endogenous secreted $\mathrm{APP}_{\mathrm{s}}$ from conditioned media of the same cells with antibody B5. No shifts in the molecular weights of PS-1 or PS-2 were obtained, while $\mathrm{APP}_{\mathrm{s}}$ isolated from the media of the same cells revealed the expected shift by approximately $2 \mathrm{kD}$. Two APP polypeptides were observed, most likely representing endogenous $\beta A \mathrm{AP}_{695}$ (lower band) and $\beta A \mathrm{AP}_{751}$ (upper band). (D) Treatment with N-glycosidase F. [ ${ }^{35}$ S]-methionine-labeled PS-1 and PS-2 were precipitated from lysates of transfected cells with antibody BOS4627, and secreted $\mathrm{APP}_{\mathrm{s}}$ was precipitated from conditioned media of the same cells with antibody B5. Immunoprecipitates were incubated for $16 \mathrm{hr}$ at $37^{\circ} \mathrm{C}$ in absence or presence of 2 units of N-glycosidase F. No shifts in the molecular weights of PS-1 or PS-2 were obtained, while APP isolated $_{\mathrm{s}}$ from the media of the same cells revealed the expected shift by approximately $2 \mathrm{kD}$. Two APP ${ }_{\mathrm{s}}$ polypeptides were observed, most likely representing endogenous $\beta \mathrm{APP}_{695}$ (lower band) and $\beta \mathrm{APP}_{751}$ (upper band). 
$\mathbf{A}$

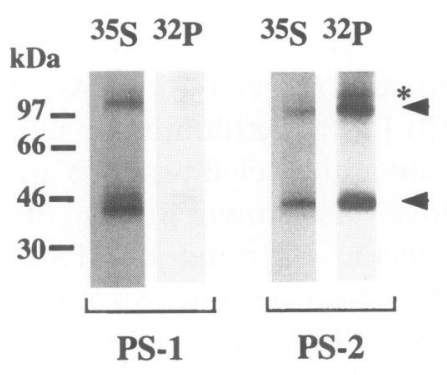

C

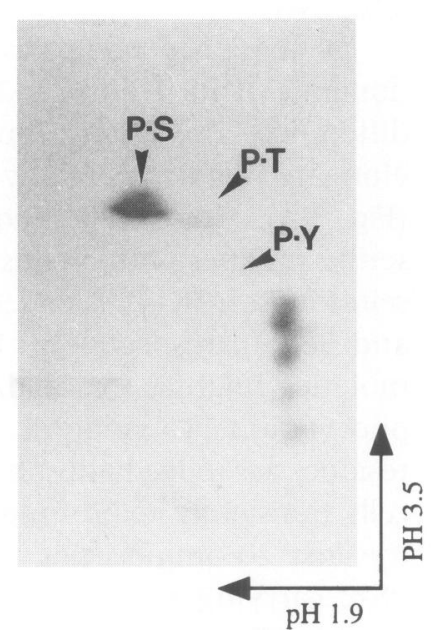

B

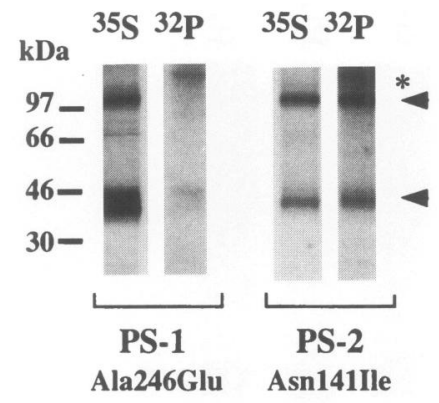

D

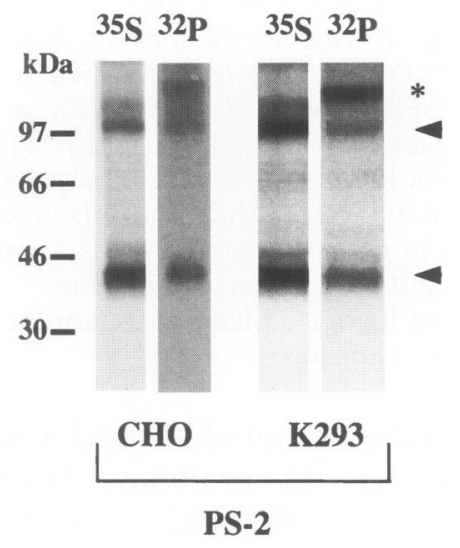

FIG. 6. In vivo phosphorylation of PS-2

(A) Phosphorylation of PS-2 proteins. COS-7 cells transfected with the PS-1 and PS-2 CDNA, respectively, were in vivo labeled with either $\left[{ }^{35} \mathrm{~S}\right]$-methionine or $\left[{ }^{32} \mathrm{P}\right]$-orthophosphate. Cell lysates were immunoprecipitated with antibody BOS4627. Very little if any phosphate incorporation was observed for the PS-1 protein, whereas PS-2 proteins are strongly phosphorylated. The $\sim 100-\mathrm{kD}$ protein $(*)$ is also observed in mock-transfected cells labeled with $\left[{ }^{32} \mathrm{P}\right]$-orthophosphate. Arrowheads indicate the putative PS monomers and dimers. Oligomers of higher molecular weight were revealed after longer exposure. (B) Very little phosphate incorporation of mutant PS-1 containing the Ala246Glu mutation (FAD 1) was observed, whereas PS-2 containing the Asnl41Ile mutation (Volga Germans) is phosphorylated similar to wt PS-2. COS-7 cells were transfected with the corresponding cDNA constructs and metabolically labeled with either $\left[{ }^{35} \mathrm{~S}\right]$-methionine or $\left[{ }^{32} \mathrm{P}\right]$-orthophosphate. Cell lysates were immunoprecipitated with antibody BOS4627. The $\sim 100-\mathrm{kD}$ protein labeled by an asterisk is also detected in mock transfected cells. Arrowheads indicate the putative PS monomers and dimers. Oligomers of higher molecular weight were revealed after longer exposure. (C) Phosphoamino acid analysis of in vivo phosphorylated PS-2 protein. PS-2 is phosphorylated on serine residues. The position of phospho-serine, -theronine, and -tyrosine standards is indicated. (D) Phosphorylation of PS-2 occurs in kidney 293 cells as well as in CHO cells transfected with the PS- 2 cDNA. After metabolic labeling with either $\left[{ }^{35} \mathrm{~S}\right]$-methionine or $\left[{ }^{32} \mathrm{P}\right]$-orthophosphate, cell lysates were immunoprecipitated with antibody BOS4627. The $\sim 100-\mathrm{kD}$ protein $(*)$ is also detected in mock-transfected cells. Arrowheads indicate the putative PS monomers and dimers. Oligomers of higher molecular weight were revealed after longer exposure.

\section{Identification of the in Vivo} Phosphorylation Sites of PS-2

In order to identify the phosphorylated domain of the PS-2 protein, we introduced serial dele- tions by inserting stop codons after TM7, TM6, TM5, and TM4 as described in Fig. 4. COS-7 cells transfected with these cDNA constructs were then metabolically labeled with either $\left[{ }^{35} \mathrm{~S}\right]$-me- 


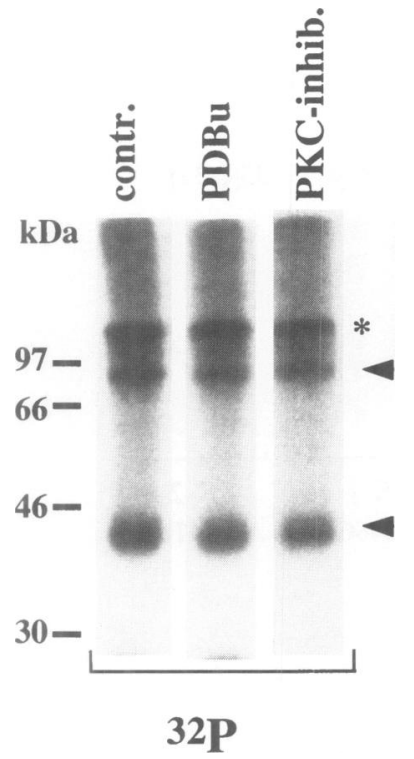

FIG. 7. Stimulation or inhibition of PKC has no influence on PS-2 phosphorylation

COS-7 cells transfected with the PS- 2 cDNA were treated with either DMSO alone (control), with PDBu (to stimulate PKC), or with GF109203X, a specific inhibitor of $\mathrm{PKC}$, in the presence of $\left[{ }^{32} \mathrm{P}\right]-$ orthophosphate. Cell lysates were immunoprecipitated with antibody BOS4627. The $\sim 100-\mathrm{kD}$ protein $(*)$ is also detected in mock-transfected cells. Arrowheads indicate the putative PS monomers and dimers. Oligomers of higher molecular weight were revealed after longer exposure.

thionine or $\left[{ }^{32} \mathrm{P}\right]$-orthophosphate and cell lysates immunoprecipitated with antibody TOR519 (Fig. 1A). After $\left[{ }^{35} \mathrm{~S}\right]$-methionine labeling, we observed truncated PS-2 proteins with the expected changes in molecular weights (Fig. 8A). Interestingly, the truncated PS-2 proteins were consistently detected as closely spaced triplet bands. Labeling with $\left[{ }^{32} \mathrm{P}\right]$-orthophosphate still resulted in the detection of the corresponding phosphorylated recombinant proteins (Fig. 8A). Of the three observed polypeptides labeled with $\left[{ }^{35} \mathrm{~S}\right]$-methionine, only the two higher bands were phosphorylated (Fig. 8A). The observed molecular weight difference between the three polypeptides is very little, which might explain why these triplets can not be observed after expressing the wildtype PS-2 cDNA or the PS-2TM7 cDNA construct. It is important to note that the corresponding truncated PS- 1 proteins migrate as single bands (Fig. 1D), suggesting that the two additional polypeptides observed for the deleted PS-2 proteins are due to their selective phosphorylation. Taken together, these experiments show that PS-2 phosphorylation sites must be located between the $\mathrm{N}$ terminus and the putative TM4 domain.
To identify the phosphorylated domain more precisely, we constructed hybrid molecules, by exchanging the $\mathrm{N}$ terminus of PS- 1 with that of PS- 2 and vice versa (for details see Materials and Methods). COS-7 cells, transiently transfected with the respective cDNAs, were labeled either with $\left[{ }^{35} \mathrm{~S}\right]$-methionine or with $\left[{ }^{32} \mathrm{P}\right]$-orthophosphate and labeled proteins analyzed as described above. As shown in Fig. 8B, the PS-1 hybrid molecule, carrying the PS- $2 \mathrm{~N}$ terminus (PS1/NT PS-2) becomes strongly phosphorylated in contrast to the native PS-1 protein. On the other hand, phosphorylation of the PS-2 hybrid molecule, carrying the $\mathrm{N}$ terminus of PS-1 (PS-2/NT PS-1), was clearly reduced, compared with the phosphorylation of wild-type PS-2. These data indicate that the in vivo phosphorylation of native PS- 2 proteins occurs between its $\mathrm{N}$ terminus and TMl.

A sequence comparison of the $\mathrm{N}$-terminal domains of PS- 1 and PS-2 reveals an intriguing difference. The $\mathrm{N}$ terminus of PS-2 includes an elongated acidic stretch, which is missing in PS-I (Fig. 9A). This acidic sequence contains three serine residues with a consensus sequence for casein kinase (CK)-1 (Ser 19) and for CK-2 (Ser 7 and Ser 9), respectively. Therefore these serine moieties might be candidates for in vivo phosphorylation. To analyze whether these serine residues are indeed phosphorylated in vivo, COS-7 cells transiently expressing PS-2 proteins lacking the first 20 amino acids (PS-2 $\Delta$ as) or full-length PS-2 carrying a double mutation, where serine residues 7 and 9 were changed to alanine residues (PS-2Ser7,9Ala; Fig. 9A), were labeled with $\left[{ }^{35} \mathrm{~S}\right]$-methionine or $\left[{ }^{32} \mathrm{P}\right]$-orthophosphate. Labeled proteins were analyzed by autoradiography and phosphor-imaging. Although both proteins were expressed in comparable amounts to wild-type PS-2, as judged by $\left[{ }^{35} \mathrm{~S}\right]$-methionine label, phosphorylation of PS-2 $\Delta$ as lacking the first 20 amino acids was significantly reduced by approximately 90-95\% (Fig. $9 \mathrm{~B}$ and C). In contrast, phosphate incorporation into full-length PS-2 protein carrying the double mutation (Ser 7,9 Ala) was reduced only by approximately $60 \%$ (Fig. $9 \mathrm{~B}$ and C). These data strongly suggest that the three serine residues (Ser 7, Ser 9, and Ser 19) represent phosphorylation sites in vivo. Mutagenesis of serines 7 and 9 to alanine removes only two phosphor acceptor sites therefore resulting in the reduction of two-thirds of phosphate incorporation. To support further the involvement of CK-1 and CK-2 in the phosphorylation of PS-2, we tested if a GST-fusion- 


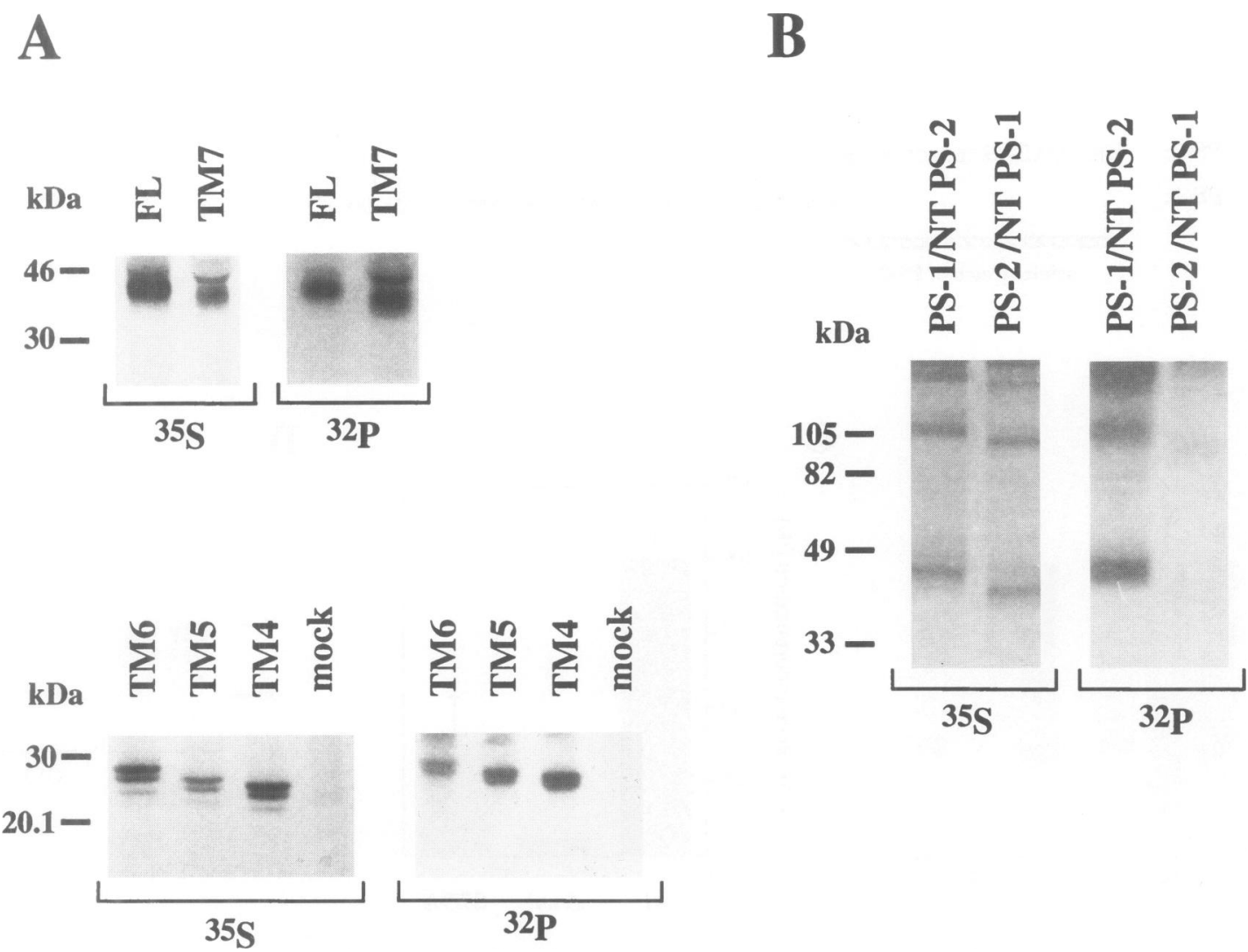

FIG. 8. Phosphorylation of PS-2 occurs within the $\mathbf{N}$-terminal domain

(A) COS-7 cells transfected with either wt PS-2 or with the PS-2 cDNA constructs containing the C-terminal deletion constructs described in Fig. 4 were metabolically labeled with $\left[{ }^{35} \mathrm{~S}\right]$-methionine or $\left[{ }^{32} \mathrm{P}\right]$-orthophosphate. Cell lysates were immunoprecipitated with antibody TOR519. Recombinant PS proteins derived from all deletion constructs are still phosphorylated indicating that PS-2 phosphorylation occurs between the N-terminus and TM4. Note that only the two higher-molecular weight peptides of the three observed by $\left.{ }^{35} \mathrm{~S}\right]$-methionine labeling are phosphorylated. wt PS-2 as well as the TM7 derived PS-2 proteins were separated on 8\% SDS/urea gels, all other recombinant PS-2 proteins were separated on $10 \%$ SDS/urea gels. (B) Hybrid molecules were generated by exchanging the $\mathrm{N}$ terminus of PS-1 with that of PS-2 (PS-1/NT PS-2) and vice versa (PS-2/NT PS-1). COS-7 cells were transfected with these cDNA constructs and metabolically labeled with $\left[{ }^{35} \mathrm{~S}\right]$-methionine or $\left[{ }^{32} \mathrm{P}\right]-$-orthophosphate. Strikingly, PS-1 containing the N-terminal domain of PS-2 is heavily phosphorylated, whereas little phosphate incorporation was observed for PS-2 containing the N-terminal domain of PS-1.

protein carrying the $\mathrm{N}$ terminus of PS-2 could serve as substrate for these protein kinases. As shown in Fig. 9D, CK-1 as well as CK-2 phosphorylate the fusionprotein in vitro within the N-terminal domain of PS-2, whereas no phosphate incorporation was observed in the GST protein itself. Phosphoamino acid analysis revealed that exclusively serine residues were phosphorylated, which is consistent with our in vivo data. Moreover, a GST fusion protein carrying the double serine mutation was not phosphorylated by CK-2 in vitro, whereas phosphorylation by $\mathrm{CK}-1$ was still observed (data not shown). Taken together with the results from the mutagenesis experiments, the in vitro data suggest that CK- 1 and CK- 2 are potential candidates for PS-2 phosphorylation in vivo.

\section{DISCUSSION}

Information about the biochemistry and cell biology of PS proteins is required to understand their biological and pathological functions in vivo. We therefore analyzed the subcellular localization of PS proteins, searched for potential ER retention signals within the PS proteins, and analyzed post-translational modifications, specifically phosphorylation.

As demonstrated by in vivo labeling as well as pulse-chase experiments in transiently transfected tissue culture cells, PS- 1 and PS-2 do not undergo maturation and protein sulfation. The lack of posttranslational modifications such as sulfation is consistent with the subcellular localization of the PS proteins. Immunoflourescence 
A

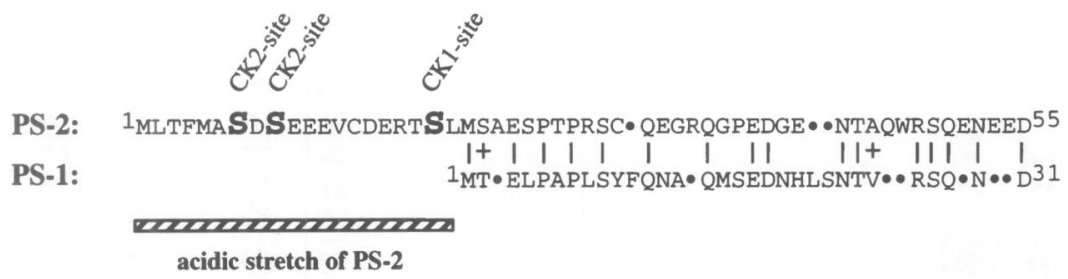

B

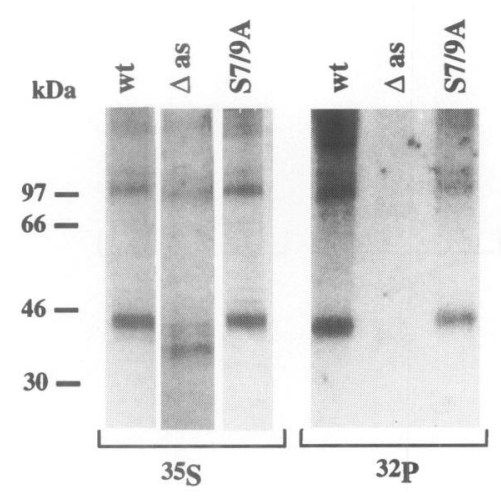

C

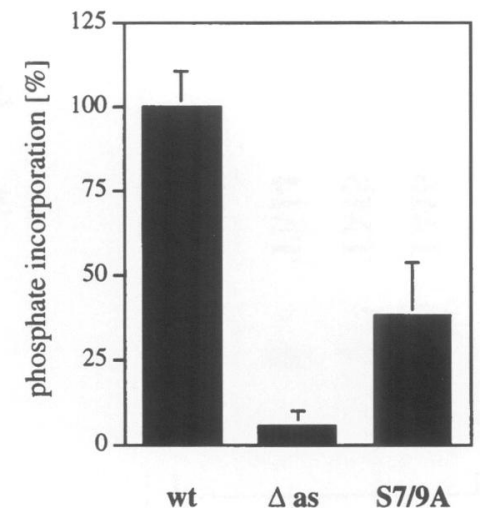

D

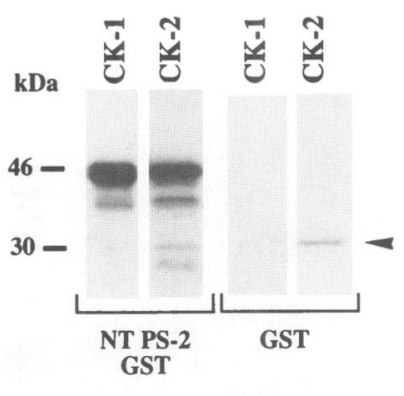

FIG. 9. Identification of the PS-2 phosphorylation sites and potential candidate kinases

(A) Sequence comparison of the N-terminal domain of PS-1 and PS-2. Three serine residues (S) are located within a stretch of acidic amino acids (underlined by a striped bar) of PS- 2 which is absent in PS- 1 . The three serine residues are potential substrates for CK-2 (Ser 7 and Ser 9) and CK-1 (Ser 19). (B) COS-7 cells transfected with the cDNA constructs PS-2 $\Delta$ as (which deletes the entire acid stretch shown in Panel A) and PS-2 Ser7/9Ala (which exchanges serine residues 7 and 9 by alanine) were metabolically labeled with $\left[{ }^{35} \mathrm{~S}\right]$-methionine or $\left[{ }^{32} \mathrm{P}\right]$-orthophosphate and immunoprecipitated with antibody BOS4627. The deletion of the acidic stretch significantly inhibits phosphate incorporation, whereas single point mutations at serine residues 7 and 9 result only in a partial reduction of phosphate incorporation. (C) Quantitation of the results shown in Panel B. The deletion of the acidic stretch results in an almost complete inhibition of phosphate incorporation, whereas the two point mutations at serine residues 7 and 9 remove only two-thirds of the phosphate incorporation. Bars $=$ mean \pm SEM of three to four independent experiments. (D) GST fusion proteins with (NT PS-2 GST) or without the N terminus of PS-2 (GST) were phosphorylated in vitro with recombinant CK-1 and CK-2. Both enzymes phosphorylated the GST fusion protein with the $\mathrm{N}$ terminus of PS-2, whereas no phosphorylation was observed if GST alone was added to the in vitro assay. Arrowhead indicates autophosphorylation of the $\beta$-subunit of CK-2 (43).

data indicate that both proteins reside predominantly within the ER, whereas sulfation as well as posttranslational glycosylation of proteins are known to take place in late Golgi compartments (39). These data also confirm the results by Kovacs et al. (29). In this study, flagged PS-2 molecules were detected in reticulate structures believed to represent the ER. This is now proven by double-labeling experiments using cDNAs encoding native PS-1 and PS-2. The reason for ER retention of the PS proteins is not known. It has been speculated that a conserved aspartate residue in TM6 of PS-1 and PS-2 might represent an ER retention signal, as shown for other proteins (44). However, deleting the entire TM6 and the following C-terminal sequence did not alter the predominant ER localization of both PS proteins, indicating that neither the conserved aspartate residue nor the large hydrophilic loop plays a major role in the ER retention of PS proteins. It is therefore possible that intracellular complex formation of PS proteins by itself could be sufficient for the observed ER retention. These data would be supported by the recent observation that PS proteins are detected as focal clusters within ER membranes of primate cerebellum (St. GeorgeHyslop, personal communication). However, ER retention of the PS proteins might also be achieved by interaction with specific binding proteins forming heteromeric complexes. 
Interestingly, in transfected cells we also detected small amounts of PS proteins within the Golgi compartment where colocalization with $\beta A P P$ was shown. These data might therefore indicate a direct interaction of $\beta$ APP and PS proteins within the Golgi. However, in untransfected cells PS proteins were only detected within the ER. This might indicate that overexpression of PS proteins in transfected cells could saturate the ER retention mechanism for PS proteins. Alternatively, the amount of endogenous PS proteins might be too low to allow their detection within the Golgi.

Despite the similarities between PS-1 and PS-2 concerning their subcellular localization and their lack of sulfation and glycosylation, we were able to demonstrate a striking difference between the two proteins in regard to phosphorylation. In vivo labeling with $\left[{ }^{32} \mathrm{P}\right]$-orthophosphate revealed a significant phosphorylation of PS-2 on serine residues, while very little phosphate incorporation was observed for PS-1. It was reported that potential PKC recognition sequences are present within the PS amino acid sequence (17). PKC-dependent phosphorylation of the PS proteins would be very interesting, because this could provide a direct link to PKCdependent regulation of $\beta$ APP processing and $\mathrm{A} \beta$ generation. Upon PKC stimulation, $\alpha$-secretory processing of $\beta$ APP is strongly increased $(42,45)$, whereas $\mathrm{A} \beta$ production is significantly reduced $(35,46)$. However, the data presented here disfavor a direct phosphorylation of the native PS proteins by $\mathrm{PKC}$, because stimulation of PKC with the phorbol ester PDBu as well as selective PKC inhibition had no influence on PS-2 phosphorylation.

Using C-terminal deleted forms of PS-2, and hybrid molecules of PS- 1 and PS-2, the selective phosphorylation of PS-2 was mapped to its $\mathrm{N}$ terminus. Although highly homologous throughout the whole amino acid sequence, the $\mathrm{N}$ termini of PS- 1 and PS-2 show significant differences. Especially, the first 20 amino acids of PS- 2 include a cluster of acidic residues, which is absent in PS- 1 . This acidic stretch contains two potential phosphorylation sites for CK-2 (Ser7 and Ser9) and one for CK-1 (Ser19). By investigating the phosphorylation of PS-2 proteins lacking the acidic stretch or carrying point mutations where serine residues are substituted by alanine residues we showed that serines 7,9 , and 19 are phosphorylated in vivo. In addition, we demonstrated that GST-fusionproteins carrying the PS- $2 \mathrm{~N}$ terminus can be phosphorylated in vitro by both $\mathrm{CK}-1$ and CK-2. These results strongly suggest a modification of PS- 2 by these protein kinases in vivo. Mapping of PS-2 phosphorylation to its $\mathrm{N}$ terminus also gives hinds to the topology of PS proteins. Since CK-1 and CK-2 are known to be localized in the cytoplasm $(47,48)$, the $\mathrm{N}$ terminus of PS-2 and, consequently, that of PS-1 are likely to be directed toward the cytoplasmic face of the ER. Assuming a seven transmembrane structure of PS proteins, the large hydrophilic loop should be exposed to the cytoplasm as well. However, this model clearly requires further confirmation.

The functional consequences of PS-2 phosphorylation are unknown so far. It has been reported recently that furin, a transmembrane serine protease is phosphorylated in its cytoplasmic domain by a CK-2 activity associated with the rough ER (49). CK-2-mediated phosphorylation was shown to modulate the subcellular localization of furin. Whether the phosphorylation or dephosphorylation of PS-2 results in alterations of PS-2 function or localization remains to be determined. However, based on light microscopy no differences in the localization of phosphorylated and unphosphorylated PS-2 were found. The involvement of two different protein kinases, phosphorylating PS-2 at distinct amino acids provides a mechanism for a highly controlled and fine-tuned regulation. Whether the specific phosphorylation of PS-2 in an acidic $\mathrm{N}$-terminal sequence, which is absent in PS- 1 , determines different biological functions of the two highly homologous PS proteins will also be of great interest.

Note Added in Proof: While this manuscript was under review similar data were obtained by De Strooper et al. (submitted) and Cook et al. (Proc. Acad. Sci. U.S.A.: 9223-9228, 1996).

\section{ACKNOWLEDGMENTS}

This work was supported by grants from the Deutsche Forschungsgemeinschaft (SFB317HA 1737/2-1; MU 467/8-1), by the Boehringer Ingelheim KG. (to $\mathrm{CH}$ ), by National Institutes of Health Grants AG 06173 and AG 12749 (to DJS), and by the Alzheimer Association of Ontario, the Medical Research Council of Canada and the Canadian Genetic Disease Network (to PSH). We thank Dr. Walter Pyerin for providing human recombinant CK-2, Dr. Edward Koo for providing monoclonal antibodies to $\beta A P P$, Dr. Dale 
Schenk for providing antibody B5, and Dr. Martin Citron for critical comments and discussion.

\section{REFERENCES}

1. Selkoe DJ. (1994) Normal and abnormal biology of the $\beta$-amyloid precursor protein. Annu. Rev. Neurosci. 17: 489-517.

2. Cummings BJ, Cotman CW. (1995) Image analysis of $\beta$-amyloid load in Alzheimer's disease and relation to dementia severity. Lancet 346: 1524-1528.

3. Kang J, Lemaire H-G, Unterbeck A, et al. (1987) The precursor of Alzheimer's disease amyloid A4 protein resembles a cell-surface receptor. Nature 325: 733-736.

4. Price DL, Sisodia SS, Gandy SE. (1995) Amyloid $\beta$ amyloidosis in Alzheimer's disease. Curr. Opin. Neurol. 8: 268-274.

5. Goate A, Chartier-Harlin MC, Mullan M, et al. (1991) Segregation of a missense mutation in the amyloid precursor gene with familial Alzheimer's disease. Nature 349: 704706.

6. Schellenberg GD, Bird TD, Wijsman E, et al. (1992) Genetic linkage evidence for a familial Alzheimer disease locus on chromosome 14. Science 3: 1-4.

7. St. George-Hyslop P, Haines J, Rogaev E, et al. (1992) Genetic evidence for a novel familial Alzheimer's disease locus on chromosome 14. Nat. Genet. 2: 330-334.

8. van Broeckhoven $\mathrm{C}$, Backhovens $\mathrm{H}$, Cruts M, et al. (1992) Mapping of a gene predisposing to early-onset Alzheimer's disease to chromosome 14q24.3. Nat. Genet. 2: 335-339.

9. Levy-Lahad E, Wijsman EM, Nemens E, et al. (1995) A familial Alzheimer's disease locus on chromosome I. Science 269: 970-973.

10. Strittmatter WJ, Roses AD. (1995) Apolipoprotein $\mathrm{E}$ and Alzheimer's disease. Proc. Natl. Acad. Sci. U.S.A. 92: 4725-4727.

11. Mullan M, Crawford F. (1993) Genetic and molecular advances in Alzheimer's disease. Trends Neurosci. 16: 398-414.

12. Haass C, Selkoe DJ. (1993) Cellular processing of $\beta$-amyloid precursor protein and the genesis of amyloid $\beta$-peptide. Cell 75: 10391042.

13. Citron M, Oltersdorf T, Haass C, et al. (1992) Mutation of the $\beta$-amyloid precursor protein in familial Alzheimer's disease increases $\beta$-protein production. Nature 360: 672-674.

14. Cai XD, Golde TE, Younkin SG. (1993) Re- lease of excess amyloid $\beta$ protein from a mutant amyloid $\beta$ protein precursor. Science 259: 514-516.

15. Haass C, Hung AY, Selkoe DJ, Teplow DB. (1994) Mutations associated with a locus for familial Alzheimer's disease result in alternative processing of amyloid $\beta$-protein precursor. J. Biol. Chem. 269: 17741-17748.

16. Suzuki N, Cheung TT, Cai XD, et al. (1994) An increased percentage of long amyloid $\beta$ protein secreted by familial amyloid $\beta$ protein precursor $\left(\beta \mathrm{APP}_{717}\right)$ mutants. Science 264: $1336-1340$.

17. Sherrington R, Rogaev EI, Liang $Y$, et al. (1995) Cloning of a gene bearing missense mutations in early-onset familial Alzheimer's disease. Nature 375: 754-760.

18. Levy-Lahad E, Wasco W, Poorkaj P, et al. (1995) Candidate gene for the chromosome I familial Alzheimer's disease locus. Science 269: 973-977.

19. Rogaev EI, Sherrington R, Rogaeva EA, et al. (1995) Familial Alzheimer's disease in kindreds with missense mutations in a gene on chromosome 1 related to the Alzheimer's disease type 3 gene. Nature 376: 775-778.

20. Haass C (1996) Presenile because of presenilin: The presenilin genes and early dementia. Curr. Opin. Neurol. 9: 254-259.

21. Alzheimer's Disease Collaborative Group. (1995) The structure of the presenilin 1 (S 182) gene and identification of six novel mutations in early onset AD families. Nat. Genet. 11: 219-222.

22. Cruts $M$, Hendriks $L$, van Broeckhoven $C$. (1996) The presenilin genes: A new family involved in Alzheimer's disease pathology. Hum. Mol. Genet. 5: 1449-1455.

23. Cruts $M$, Backhovens $H$, Wang SY, et al. (1995) Molecular genetic analysis of familial early-onset Alzheimer's disease linked to chromosome 14q24.3. Hum. Mol. Genet. 4: 2363-2371.

24. Campion D, Flaman JM, Brice A, et al. (1995) Mutations of the presenilin 1 gene in families with early-onset Alzheimer's disease. Hum. Mol. Genet. 4: 2373-2377.

25. Wasco W, Pettingell WP, Jondro PD, et al. (1995) Familial Alzheimer's chromosome 14 mutations. Nat. Med. 1: 848.

26. Boteva K, Vitek M, Mitsuda H, et al. (1996) Mutation analysis of the presenilin 1 gene in Alzheimer's disease. Lancet 347: 130-131.

27. Perez-Tur J, Froelich S, Prihar G, et al. (1995) A mutation in Alzheimer's disease 
destroying a splice acceptor site in the presenilin-1 gene. NeuroReport 7: 297-301.

28. Hutton M, Busfield F, Clark R, et al. (1996) Complete analysis of the presenilin-1 gene in families with early-onset Alzheimer's disease. NeuroReport 7: 130-131.

29. Kovacs DM, Fausett HJ, Page KJ, et al. (1996) Alzheimer-associated presenilins 1 and 2: Neuronal expression in brain and localization to intracellular membranes in mammalian cells. Nat. Med. 2: 224-229.

30. Suzuki T, Nishiyama $K$, Murayama $S$, et al. (1996) Regional and cellular presenilin 1 gene expression in human and rat tissues. Biochem. Biophys. Res. Commun. 219: 708-713.

31. L'Hernault SW, Arduengo PM. (1992) Mutation of a putative sperm membrane protein in Caenorhabditis elegans prevents sperm differentiation but not its associated meiotic divisions. J. Cell Biol. 119: 55-68.

32. Levitan D, Greenwald I. (1995) Facilitation of lin-12-mediated signaling by sel-12, a Caenorhabditis elegans S182 Alzheimer's disease gene. Nature 377: 351-354.

33. Podlisny MB, Tolan DR, Selkoe DJ. (1991) Homology of the amyloid beta protein precursor in monkey and human supports a primate model for beta amyloidosis in Alzheimer's disease. Am. J. Pathol. 138: 14231435.

34. Haass C, Hung AY, Selkoe DJ. (1991) Processing of $\beta$-amyloid precursor protein in microglia and astrocytes favors an internal localization over constitutive secretion. J. Neurosci. 11: 3783-3793.

35. Hung AY, Haass C, Nitsch RM, et al. (1993) Activation of protein kinase $C$ inhibits cellular production of the amyloid $\beta$-protein. J. Biol. Chem. 268: 22959-22962.

36. Boyle WJ, van der Geer P, Hunter T. (1991) Phosphopeptide mapping and phosphoamino acid analysis by two-dimensional separation on thin-layer cellulose plates. Methods Enzymol. 201: 110-149.

37. Haass C, Lemere C, Capell A, et al. (1995) The Swedish mutation causes early onset Alzheimer's disease by $\beta$-secretase cleavage within the secretory pathway. Nat. Med. 1: 1291-1296.

38. Koo EH, Squazzo S. (1994) Evidence that production and release of amyloid $\beta$-protein involves the endocytic pathway. J. Biol. Chem. 269: 17386-17389.
39. Huttner WB. (1987) Proteine tyrosine sulfation. TIBS 12: 361-363.

40. Weidemann A, König G, Bunke D, et al. (1989) Identification, biogenesis, and localization of precursors of Alzheimer's disease A4 amyloid protein. Cell 57: 115-126.

41. Roche KW, Tingley WG, Huganir RL. (1994) Glutamate receptor phosphorylation and synaptic plasticity. Curr. Opin. Neurobiol. 4: 383-388.

42. Buxbaum JD, Gandy SE, Cicchetti $P$, et al. (1990) Processing of Alzheimer $\beta /$ A4 amyloid precursor protein: Modulation by agents that regulate protein phosphorylation. Proc. Natl. Acad. Sci. U.S.A. 87: 6003-6006.

43. Bodenbach L, Fauss J, Robitzki A, et al. (1994) Recombinant human Casein Kinase II: A study with a complete set of subunits $\left(\alpha, \alpha^{\prime}\right.$, and $\left.\beta\right)$ site directed autophosphorylation mutants and a bicistronically expressed holoenzyme. Eur. J. Biochem. 220: 262-273.

44. Bonifacino JS, Cosson P, Sha N, Klausner RD. (1994) Calnexin: a membrane bound chaperone of the endoplasmic reticulum. TIBS 19: 1124-1128.

45. Nitsch RM, Slack BE, Wurtman RJ, Growdon JH. (1992) Release of Alzheimer amyloid precursor derivatives stimulated by activation of muscarinic acetylcholine receptors. Science 258: 304-307.

46. Buxbaum JD, Koo EH, Greengard P. (1993) Protein phosphorylation inhibits production of Alzheimer amyloid $\beta /$ A4 peptide. Proc. Natl. Acad. Sci. U.S.A. 90: 9195-9198.

47. Lorenz P, Pepperkok R, Ansorge W, Pyerin W. (1993) Cell biological studies with monoclonal and polyclonal antibodies against human casein kinase II subunit $\beta$ demonstrate participation of the kinase in mitogenic signaling. J. Biol. Chem. 268: 90-97.

48. Issinger OG. (1993) Casein kinases: Pleiotropic mediators of cellular regulation. Pharmacol. Ther. 59: 1-30.

49. Jones BG, Thomas L, Molloy SS, et al. (1995) Intracellular trafficking of furin is modulated by the phosphorylation state of a casein kinase II site in its cytoplasmic tail. EMBO J. 14: 5869-5883.

50. Tartakoff AM, Vassali P. (1983) Lectin-binding sites as markers of Golgi subcompartments: Proximal-to-distal maturation of oligisaccharides. J. Cell Biol. 97: 1243-1248. 